\title{
Estrogen-Dependent Functional Spine Dynamics in Neocortical Pyramidal Neurons of the Mouse
}

\author{
ㄴengyou Ye, Robert H. Cudmore, and ${ }^{-D a v i d}$ J. Linden \\ The Solomon H. Snyder Department of Neuroscience, Johns Hopkins University School of Medicine, Baltimore, Maryland 21205
}

\begin{abstract}
Surgical ovariectomy has been shown to reduce spine density in hippocampal CA1 pyramidal cells of rodents, and this reduction is reversed by $17 \beta$-estradiol (E2) treatment in a model of human estrogen replacement therapy. Here, we report reduction of spine density in apical dendrites of layer 5 pyramidal neurons of several neocortical regions that is reversed by subsequent $\mathrm{E} 2$ treatment in ovariectomized (OVX) female Thy1M-EGFP mice. We also found that OVX-associated reduction of spine density in somatosensory cortex was accompanied by a reduction in miniature EPSC (mEPSC) frequency (but not mIPSC frequency), indicating a change in functional synapses. OVX-associated spine loss in somatosensory cortex was also rescued by an agonist of the G-protein-linked estrogen receptor (GPER) but not by agonists of the classic estrogen receptors $\mathrm{ER} \alpha / \mathrm{ER} \beta$, whereas the opposite selectivity was found in area CA1. Acute treatment of neocortical slices with $\mathrm{E} 2$ also rescued the OVX-associated reduction in mEPSC frequency, which could be mimicked by a GPER agonist and abolished by a GPER antagonist. Time-lapse in vivo two-photon imaging showed that OVX-associated reduction in spine density is achieved by both an increase in spine loss rate and a decrease in spine gain rate and that subsequent rescue by $\mathrm{E} 2$ reversed both of these processes. Crucially, the spines added after E2 rescue were no more likely to reappear at or nearby the sites of pre-OVX spines than those in control mice treated with vehicle. Thus, a model of estrogen replacement therapy, although restoring spine density and dynamics, does not entirely restore functional connectivity.
\end{abstract}

Key words: dendrite; estradiol; estrogen; ovariectomy; spine; synapse

Significance Statement

Estrogen replacement therapy following menopause or surgical removal of the ovaries is a widespread medical practice, yet little is known about the consequences of such treatment for cells in the brain. Here, we show that estrogen replacement reverses some of the effects of surgical removal of the ovaries on the structure and function of brain cells in the mouse. Yet, importantly, the fine wiring of the brain is not returned to the presurgery state by estrogen treatment, suggesting lasting functional consequences.

\section{Introduction}

Many lines of evidence, from anatomical, electrophysiological and behavioral experiments, have indicated that brain circuits retain their ability to be modified by experience throughout life and that this process is central to memory storage. A large part of the experience-driven modification of neural circuits involves persistent alterations of synaptic strength as well as the elimination and formation of synapses (Chen et al., 2014; but see Berry

Received Oct. 26, 2018; revised April 9, 2019; accepted April 11, 2019.

Author contributions:Z.Y., R.H.C., and D.J.L. designed research;Z.Y. performed research; Z.Y. and R.H.C. analyzed data; R.H.C. contributed unpublished reagents/analytic tools; Z.Y. and D.J.L. wrote the paper.

This work was supported by a Synergy Grant from Johns Hopkins University, NIH R21 NS095879 to D.J.L. and NIH P30 NS050274 to the Johns Hopkins Neuroscience Imaging Core. We thank Greg Ball and coworkers for advice on estrous cycle assessment and to Julia Brill, Hilena Gebre, Devorah Vanness, Terry Shelley, and Michele Pucak for experimental and technical support.

The authors declare no competing financial interests.

Correspondence should be addressed to David J. Linden at dlinden@jhmi.edu.

https://doi.org/10.1523/JNEUROSCI.2772-18.2019

Copyright $\odot 2019$ the authors and Nedivi, 2017). The major excitatory neurotransmitter in the mammalian brain is glutamate and most glutamatergic synapses are received on dendritic spines, which are small protrusions, typically emitted from the shafts of dendrites.

Since the early 1990s, it has been established that surgical ovariectomy (OVX) leads to a $\sim 25 \%$ loss of spine and synapse density in the apical dendrites of CA1 hippocampal pyramidal neurons (Gould et al., 1990; Woolley and McEwen, 1993; Wallace et al., 2006; Zhou et al., 2010). This synapse loss can be reversed by $17 \beta$-estradiol (E2) treatment (Gould et al., 1990; Woolley et al., 1990; Woolley and McEwen, 1993; MacLusky et al., 2005; Wallace et al., 2006; Phan et al., 2012; Luine et al., 2018). E2 treatment not only restores synapse and spine density but also increases the fraction of presynaptic terminals that form synapses with more than one dendritic spine (called multiple synapse boutons; Woolley et al., 1996) and more than one postsynaptic cell (Yankova et al., 2001).

The action of estrogens in the brain were initially thought to result solely from binding to nuclear estrogen receptors and sub- 
sequent regulation of transcription, a process that typically takes hours to manifest in functional changes in protein levels. More recently, it has been appreciated that binding of estrogens to non-nuclear estrogen receptors in neurons can produce rapid activation of signaling cascades and functional changes (Srivastava and Evans, 2013; Srivastava et al., 2013). In fact, systemic application of exogenous E2 to ovariectomized mice has been reported to evoke large increases in dendritic spine density within 30 min (MacLusky et al., 2005; Inagaki et al., 2012). Additionally, rapid E2-induced increases in synapse density have been observed using cultured mouse cortical neurons pretreated with chemical transcription inhibitors to rule out the contribution of changes in gene expression (Srivastava et al., 2008).

This main finding, loss of spine density in area CA1 of the rat following ovariectomy, and some form of recovery with estrogen replacement, has now been extended to other mammalian species including mice (Zhou et al., 2010; Phan et al., 2012) and nonhuman primates (Dumitriu et al., 2010). However, these efforts have been mostly limited by traditional anatomical methods, since conventional cell-visualization techniques performed in postmortem tissue lack dynamic information and preclude within-animal and within-dendrite comparisons over time (but see Wang et al., 2018).

If memory is encoded in spiny synapses and spine density fluctuates following ovariectomy and E2 replacement, then how does long-term memory persist in female mammals in the face of this fluctuation? Perhaps the storage of memory is sufficiently redundant so that the memory trace can tolerate the disruption of spine loss and regrowth. Or perhaps the spines that are lost and regrown do not contribute to the memory trace (Berry and $\mathrm{Ne}$ divi, 2017) or are only involved in the initial acquisition of memory, a process shown to be enhanced by estrogen (Daniel et al., 1997; Fader et al., 1999). Alternatively, when a spine is lost following ovariectomy, perhaps there remains a persistent signal in the tissue matrix, like a fragment of the postsynaptic density, that would seed a spine to regrow in that same spot on the dendritic shaft when E2 levels rise again in following replacement therapy. Here, we have performed OVX surgery and replacement therapy with agonists of estrogen receptors together with histology, recordings of miniature EPSCs (mEPSCs) and mIPSCs from layer 5 pyramidal neurons in brain slices and in vivo two-photon imaging of pyramidal cell dendrites to assess the functional and dynamic nature of spines together with these manipulations.

\section{Materials and Methods}

Mice, ovariectomy surgery, and hormone treatment. We used Thy1 M-GFP transgenic mice (RRID:IMSR_JAX:007788), which were chosen because they express EGFP sparsely in several types of neuron including neocortical layer 5 and hippocampal CA1 pyramidal cells (Feng et al., 2000). Virgin female mice, 2-3 months old, were distributed into the following experimental groups: intact, sham surgery, OVX surgery, and OVX followed by various hormone treatments.

The intact mice with normal estrous cycles ( $4-5 \mathrm{~d}$ per cycle with all stages presented) were used for imaging spine dynamics across the estrous cycle. The estrous cycles of the intact mice were tracked daily for at least two consecutive cycles with a wet vaginal smear technique as previously described (Caligioni, 2009). Briefly, the vagina was flushed gently for 3-5 times with a $20 \mu \mathrm{l}$ plastic pipette filled with $10 \mu \mathrm{l}$ saline. The final flush solution was collected and scored using phase contrast microscopy (Leitz). The stage of estrous cycle was assigned based on the proportion of nucleated epithelial cells, cornified squamosal cells, and leukocytes: proestrus with predominant nucleated epithelial cells, estrus with cornified squamosal cells, metestrus with all three types, and diestrus with predominant leukocytes.
For sham or OVX surgery, mice were anesthetized with a $1.5 \%$ isoflurane-oxygen mixture, and placed in a supine position on a heating pad connected to a rectal thermometer $\left(\sim 37^{\circ} \mathrm{C}\right)$. An incision was made along the abdominal line after shaving and sterilizing. Two ovaries surrounded by fat tissue were located and carefully removed for the OVX group, whereas they were left untouched for the sham group. After suturing the incision, mice were treated subcutaneously with buprenorphine $(0.01 \mathrm{mg} / \mathrm{kg}$ body weight) and the antibiotic Baytril (enrofloxacin, $2.5 \mathrm{mg} / \mathrm{kg}$ body weight) immediately. Mice were then returned to the cage and their health status was monitored closely thereafter with daily injection of buprenorphine and Baytril in the following 2-3 d. An interval of at least $14 \mathrm{~d}$ was imposed between sham or OVX surgery and experimental measurements.

For the hormone treatment groups, mice were injected daily, subcutaneously, with vehicle (100 $\mu$ l sesame oil; Sigma-Aldrich, S3547), E2 (50 $\mu \mathrm{g} / \mathrm{kg}$ body weight; Sigma-Aldrich, E8515), G-protein-coupled estrogen receptor (GPER) agonist $( \pm)-1-\left[\left(3 \mathrm{aR}^{\star}, 4 \mathrm{~S}^{\star}, 9 \mathrm{bS} \mathrm{S}^{\star}\right)-4-(6\right.$-Bromo-1, 3-benzodioxol-5-yl)-3a,4,5,9b-tetrahydro-3H-cyclopenta[c] quinolin-8yl]-ethanone (G1; $6 \mu \mathrm{g} / \mathrm{kg}$, Cayman Chemical, 10008933), or a combination of $\mathrm{ER} \alpha / \beta$ agonists propyl pyrazole triol (PPT; $1 \mathrm{mg} / \mathrm{kg}$, Tocris Bioscience, 1426) and diarylpropionitrile (DPN; $1 \mathrm{mg} / \mathrm{kg}$, Tocris Bioscience, 1494) for $5 \mathrm{~d}$. All surgical and experimental procedures were performed in accordance with the National Institutes of Health guidelines for animal research, and were approved by the Animal Care and Use Committee of The Johns Hopkins University School of Medicine.

Immunohistochemistry. Mice, anesthetized with ketamine $(100 \mathrm{mg} / \mathrm{kg})$ and xylazine $(10 \mathrm{mg} / \mathrm{kg})$, were perfused intracardially with ice-cold PBS, followed by $4 \%$ paraformaldehyde in PBS. The entire brain was dissected, postfixed in $4 \%$ paraformaldehyde overnight, and then cryoprotected with two subsequent overnight incubations with $15 \%$ and $30 \%$ sucrose in PBS at $4^{\circ} \mathrm{C}$. Brain sections ( $40 \mu \mathrm{m}$ thick) were prepared using a microtome, washed in PBS, and then blocked with 5\% normal goat serum (Jackson ImmunoResearch Laboratories 005-000-001; RRID: AB_2336983) and $0.3 \%$ Triton X-100 in PBS at room temperature for $2 \mathrm{~h}$. The sections were incubated in primary antibodies: chicken antiGFP (1:5000; Aves Labs, GFP-1010; RRID:AB_2307313), rabbit antiGPER (1:50; Alomone Labs, AER-050; RRID:AB_2340934), mouse anti-ER $\alpha$ (1:50; ThermoFisher Scientific, MA1-80216; RRID: AB_930763), or rabbit anti-ER $\beta$ (1:50; ThermoFisher Scientific, PA1310B; RRID:AB_325815) diluted in blocking buffer overnight at $4^{\circ} \mathrm{C}$. They were then washed with PBS and incubated in the secondary antibody AlexaFluor 488-labeled goat anti-chicken (1:1000; Jackson ImmunoResearch Laboratories, \#03-545-155; RRID:AB_2337390), AlexaFluor 555-labeled goat anti-mouse (1:500; ThermoFisher Scientific, A-21424; RRID:AB_141780), or AlexaFluor 633-labeled goat anti-rabbit (1:500; ThermoFisher Scientific, A-21071; RRID:AB_2535732) in blocking buffer for $2 \mathrm{~h}$ at room temperature. The sections were mounted on slides, and $z$-stacks were acquired using a custom-built two-photon microscope (for single color imaging) or Zeiss LSM 880 confocal microscope (for multicolor imaging) with a $z$-step size of $0.75 \mu \mathrm{m}$, and resolution of $1024 \times 1024$ pixels $(0.108 \times 0.108 \mu \mathrm{m} /$ pixel, dwell time $1.6 \mu \mathrm{s})$. Representative images shown in the figures are uniformly contrast enhanced, maximal $z$-stack projections of 3-4 focal planes, de-convolved using AutoQuant X3 (Media Cybernetics) with a theoretical point spread function. Because ThylM-EGFP mice label both layer $2 / 3$ and layer 5 pyramidal cells, we differentiated the apical tuft dendrites on the basis of mean spine density which was $\sim 3$-fold larger for layer $2 / 3$ cells as previously reported (Tjia et al., 2017).

Craniotomy and in vivo two-photon imaging. Two-month old mice were implanted with a $2 \times 2 \mathrm{~mm}$ cranial window overlaying the somatosensory cortex $(1.5 \mathrm{~mm}$ lateral to the midline and $1.5 \mathrm{~mm}$ caudal to bregma) as previously described (Cudmore et al., 2017). A metal plate with a center hole was attached to the skull with dental cement to allow for head fixation during time-lapse imaging (see Fig. $3 A$ ). After craniotomy surgery, mice were housed individually, and were treated subcutaneously with buprenorphine $(0.01 \mathrm{mg} / \mathrm{kg}$ body weight $)$ and the antibiotic Baytril (enrofloxacin, $2.5 \mathrm{mg} / \mathrm{kg}$ body weight) daily, for 2-3 d thereafter.

Starting $\sim 1$ month after cranial window implantation, the dendritic spines were imaged through the cranial window using a two-photon 
microscope (Sutter Instruments) equipped with a MaiTai DeepSee Laser (Spectra-Physics) tuned to $920 \mathrm{~nm}$, and a $20 \times, 1.0 \mathrm{NA}$ water-dipping objective (Zeiss). The microscope was controlled using ScanImage software v3.8 running in MATLAB (MathWorks). The head-fixed mouse was placed on the stage of a two-photon microscope under anesthesia with $1.5 \%$ isoflurane-oxygen mixture. Two to three $z$-stacks were acquired starting from the pial surface and continuing to a depth of $\sim 100$ $\mu \mathrm{m}$ with a step size of $0.75 \mu \mathrm{m}$. All images were acquired at a resolution of $1024 \times 1024$ pixels $(0.108 \mu \mathrm{m} /$ pixel; dwell time $1.6 \mu \mathrm{s})$. The same imaging volumes-of-interest were identified across many days as guided by an annotated brain surface vasculature map taken previously with a CCD camera. Because Thy1M-EGFP mice label both layer $2 / 3$ and layer 5 pyramidal cells, $z$-stacks to a depth of $\sim 500 \mu \mathrm{m}$ were acquired and projected in the $x-z$ plane to unambiguously determine the layer where the soma resided and thereby restrict our analysis to layer 5 cells. Representative images shown in the figures were contrast enhanced maximal $z$-stack projections of 3-4 focal planes, de-convolved using AutoQuant X3 (Media Cybernetics) with theoretical point spread function. Mice were excluded from the study if the cranial window became unclear during the experiments.

Patch-clamp recording in brain slices. Coronal slices containing somatosensory cortex or occipital cortex were prepared from sham or OVX mice. Mice were anesthetized with the inhalation anesthetic Isoflurane and decapitated. Coronal $300-\mu \mathrm{m}$-thick brain slices were prepared with a Leica VT1200S vibrating slicer in ice-cold sucrose dissection solution containing the following (in $\mathrm{mm}$ ): $75 \mathrm{NaCl}, 26 \mathrm{NaHCO}_{3}, 75$ sucrose, 25 glucose, $2.5 \mathrm{KCl}, 1.25 \mathrm{NaH}_{2} \mathrm{PO}_{4}, 7 \mathrm{MgCl}_{2}$, and $0.5 \mathrm{CaCl}_{2}$. Slices were initially incubated in sucrose dissection solution $32^{\circ} \mathrm{C}$ for $30 \mathrm{~min}$, and then gently transferred to normal artificial CSF (aCSF; room temperature) containing the following (in $\mathrm{mm}$ ): $124 \mathrm{NaCl}, 26.2 \mathrm{NaHCO}_{3}, 1.25$ $\mathrm{NaH}_{2} \mathrm{PO}_{4}, 2.5 \mathrm{KCl}, 20$ glucose, $1.3 \mathrm{MgCl}_{2}$, and $2.5 \mathrm{CaCl}_{2}$. All solutions were freshly prepared and bubbled with $95 \% \mathrm{O}_{2}$ and $5 \% \mathrm{CO}_{2}$.

After pre-incubation in aCSF for at least $1 \mathrm{~h}$, the brain slices were gently transferred to the recording chamber, which was perfused with $32^{\circ} \mathrm{C}$ aCSF at $3 \mathrm{ml} / \mathrm{min}$. Whole-cell voltage-clamp recordings were made from the somata of Thy1-EGFP-positive layer 5 pyramidal neurons, as identified using fluorescence microscopy, using borosilicate glass pipettes (resistance of 4-6 M $\Omega$ ) containing the following (in $\mathrm{mM}$ ): 135 Cs-methanesulfonate, $10 \mathrm{CsCl}, 10 \mathrm{HEPES}, 4 \mathrm{Mg}_{2}$-ATP, $0.4 \mathrm{Na} 2$-GTP, and 0.2 EGTA (pH 7.3 and $290 \mathrm{mOsm}$ ). In the presence of $1 \mu \mathrm{M}$ tetrodotoxin (Abcam, ab120055), mEPSCs were recorded at a holding potential of $-70 \mathrm{mV}$ and mIPSCs at $0 \mathrm{mV}$ using an AxoPatch 700B amplifier, filtered at $1-2 \mathrm{kHz}$ using low-pass filter, and digitized at $10 \mathrm{kHz}$ using Digidata 1440A (Molecular Devices). For drug treatment experiments, vehicle $(0.01 \%$ of baseline DMSO; Sigma-Aldrich, D4540) or G1 (100 $\mathrm{nM})$ were add to incubating solution for $2-3 \mathrm{~h}$ before recording. The frequency and amplitude of mEPSCs were analyzed off-line using specialized peak detection software (MiniAnalysis, Synaptosoft).

Data analysis. Spine dynamics analysis was performed blind to treatment using custom MapManager software (http://mapmanager.net) written in Igor Pro (WaveMetrics). The backbone and radius of dendritic segments were traced within the raw image stacks using a modified version of the Simple Neurite Tracer Plugin in FIJI. Spines were manually marked as a $3 \mathrm{D}$ point at their tip, and semiautomatically connected to the dendritic backbone. This connection point gives each spine a distance (in $\mu \mathrm{m}$ ) along the dendritic backbone from a manually identified fiduciary point (common to all time points) and is used to semiautomatically identify corresponding spines from one image stack to the next. Finally, the correspondence of spines between time points was visually verified and manually edited for errors. The rate of spines added and lost was calculated based on the spines that appeared or disappeared, divided by twice the total number of spines present. The turnover rate (TOR) was calculated as the sum of the spine loss rate and the spine addition rate. For a spine to be included in the final analysis, it must have protruded from the dendritic backbone by at least $0.5 \mu \mathrm{m}$ ( 5 pixels). The precisely regrown spines at pre-OVX sites were defined as spines that disappeared after OVX (Day 20) and then regrew following treatment (Day 25) within $0.3 \mu \mathrm{m}$ (3 pixels) of their previous dendritic position on the same side of the dendrite. The regrown spines nearby lost pre-OVX spines or nearby existing spines were within $0.9 \mu \mathrm{m}$ on either side of the dendrite. The regrowth rate for each dendritic segment was calculated as the number of regrown spines divided by the total number of added spines.

A model of random spine addition was constructed to estimate the probability of a new spine growing in a previously occupied position on a dendritic segment (model source code available at https://github.com/ cudmore/ye_et_al_2019). Model parameters were set using experimentally observed spine dynamics for individual dendritic segments. Each dendritic segment tracing was first split into a number of equally spaced slots (slot length $=0.6 \mu \mathrm{m}$ ) and each slot was assigned one of three categories based on the observed spine dynamics for the given segment: (1) currently occupied, (2) previously occupied, or (3) never occupied. For one model run, the number of added spines was randomly placed into individual slots without replacement (to avoid more than 1 spine per slot) and the fraction of these spines falling in previously occupied slots was tallied. To normalize between segments, the model parameters of each dendritic segment were scaled such that the number of added spines was equal to 20. This scaling included the segment length (and in turn the number of slots), the number of added spines, as well as the number of currently occupied, previously occupied, and never occupied slots. Each segment model was run 10,000 times to estimate the probability of a spine re-growing in a previously occupied slot, nearby previously occupied slots, or nearby currently occupied slots. Models across individual segments were pooled and the resulting probability density of adding a new spine in a previously occupied slot was calculated (as in Fig. 9B).

Statistics. All data are presented as the mean \pm SEM. The paired twotailed Student's $t$ test was performed for before and after comparisons. The Mann-Whitney rank sum test (Fig. 1), Kolmogorov-Smirnov twosample test (see Figs. 9B, 10B), or unpaired two-tailed Student's $t$ test were used for two-group comparisons, and one-way or two-way ANOVA (survival rate comparison) with Bonferroni's post hoc correction for multiple comparisons.

\section{Results}

Initially, we sought to use histology to survey neocortical regions in the Thy1M-GFP mouse to determine which areas show loss of dendritic spine density following OVX surgery versus sham surgery control in young adult female mice. We chose regions on the dorsal surface of the brain that would be accessible for subsequent cranial window implantation and in vivo two-photon imaging. In each neocortical region we imaged the apical tuft of layer 5 pyramidal neurons, which ramifies in layer 1 . For comparison to previously published work, we also imaged the dendrites of hippocampal CA1 pyramidal neurons within the middle $1 / 3$ of stratum radiatum, which is dominated by Schaffer collateral-CA1 synapses. Mice were killed and brains were fixed and sliced at least $15 \mathrm{~d}$ after OVX or sham surgery (Fig. 1). When the images were analyzed (by an evaluator blind to treatment) it was revealed that OVX surgery produced a significant decrease in spine density in hippocampal CA1 pyramidal cells compared with sham surgery controls $(71.80 \pm 1.70 \%$ of baseline, $p<$ 0.001 ), similar to that previously reported in rats (Gould et al., 1990; Woolley and McEwen, 1993; Wallace et al., 2006) and mice (Zhou et al., 2010). OVX-associated significant decreases in spine density were also found in frontal cortex $(61.93 \pm 2.57 \%$ of baseline, $p<0.001)$, motor cortex $(53.79 \pm 1.75 \%$ of baseline, $p<$ $0.001)$, and somatosensory cortex $(68.71 \pm 2.12 \%$ of baseline, $p<0.001)$, consistent with a previous report in rat somatosensory cortex (Chen et al., 2009). The small decrease in occipital cortex spine density produced by OVX surgery was not significant $(91.77 \pm 2.78 \%$ of baseline, $p=0.303)$.

In adult neocortex, most of the spines on the apical dendrites of layer 5 pyramidal cells receive glutamatergic presynaptic terminals as assessed by electron microscopy (Markram et al., 1997). Here, with sparse Thyl-M-GFP fluorescence, we are unable to resolve presynaptic terminals that might contact these spines. So, 


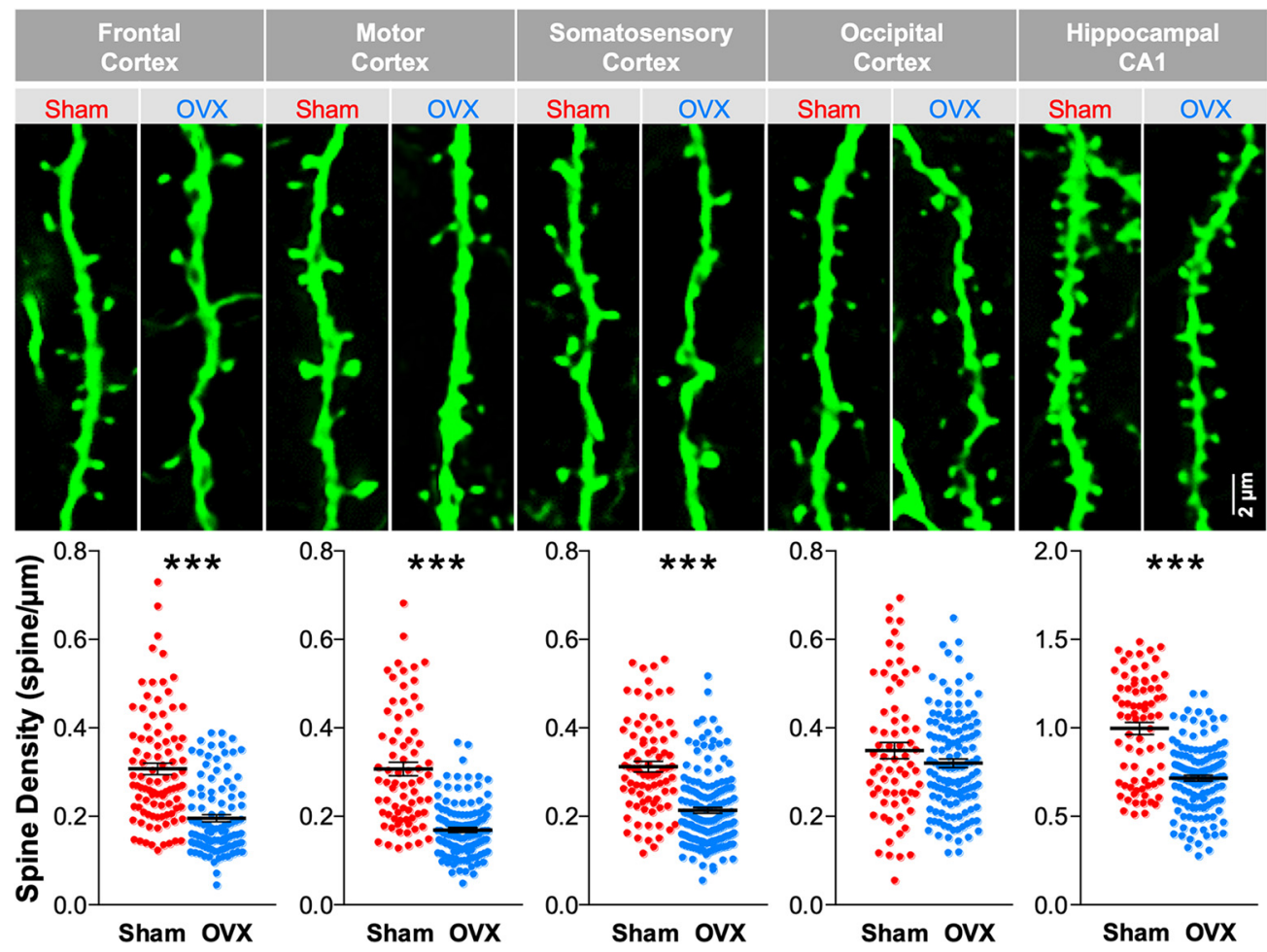

Figure 1. Surgical OVX decreases the spine density in apical dendrites of neocortical layer 5 pyramidal neurons. The representative images show spiny apical dendritic segments (residing in layer 1) of neocortical layer 5 neurons from various brain regions as well as apical dendritic segments from hippocampal CA1 pyramidal neurons in mice that have undergone either sham or OVX surgeries. These are fixed-tissue images showing immunoreactivity against EGFP in Thy1M-GFP mice. In the corresponding scatter plots, each plot point is the spine density of a dendritic segment from four sham and five OVX mice. The numbers of dendritic segment included in each group are as follows: 94 sham and 103 OVX in frontal cortex, $U=2113 ; 74$ sham and 124 OVX in motor cortex, $U=$ $1437.5 ; 80$ sham and $1580 \mathrm{VX}$ in somatosensory cortex, $U=2836 ; 68$ sham and 131 OVX in occipital cortex, $p=0.303$ and $U=4057 ; 75$ sham and 132 OVX in hippocampal CA1, $U=2397$. Mann-Whitney rank sum test was performed to analyze the significance. ${ }^{* *} p<0.001$.

to indicate whether functional glutamatergic synapses are decreased by OVX surgery, we prepared brain slices from somatosensory cortex $\sim 15 \mathrm{~d}$ after OVX or sham surgery. Then mEPSCs were recorded in the presence of tetrodotoxin to block action potentials (Fig. 2A). OVX surgery produced a significant decrease in mEPSC frequency $(64.38 \pm 8.93 \%$ of baseline, $p=0.044)$ compared with sham surgery with no significant change in mEPSC amplitude ( $97.27 \pm 5.14 \%$ of baseline, $p=0.646)$. This finding is consistent with a reduction in the total number of glutamatergic synapses received as indexed by the aforementioned reduction of density in apical dendritic spines. Two caveats should be noted: mEPSCs will reflect many glutamatergic synapses impinging upon layer 5 pyramidal cells, not just those received on spines in the apical tuft. Also, the reduction in mEPSC frequency following OVX surgery could reflect a decrease in the probability of release from these synapses or an increase in the proportion of postsynaptically-silent synapses in addition to a decrease in their number. However, mEPSC amplitude was not changed following OVX surgery (97.27 $\pm 5.14 \%$ of baseline) suggesting that the mean postsynaptic responsiveness was not altered. When these measurements were repeated from later 5 pyramidal cells in occipital cortex, no significant reduction of mEPSC frequency was observed $(94.04 \pm 8.65 \%$ of baseline, $p=$ $0.734)$, consistent with no significant reduction in spine density in the apical dendrite in that region.

When mIPSCs were measured in somatosensory cortex, no significant changes in either mIPSC frequency $(114.96 \pm 9.00 \%$ of baseline, $p=0.194)$ or amplitude $(102.42 \pm 10.08 \%$ of baseline, $p=0.344$ ) were observed (Fig. 2B). Similarly, no differences were seen in these measures in recordings of neurons from occip- ital cortex. Thus, OVX-induced synaptic changes appear to be specific for excitatory synapses (the status of neuromodulatory synapses after OVX surgery was not assessed). In addition, these findings argue against nonspecific damage to the health of layer 5 pyramidal neurons by OVX surgery as an explanation for reduced mEPSC frequency in somatosensory cortex.

To determine whether exogenous E2 could reverse the effects of OVX surgery on dendritic spine density, mice received OVX surgery and then, after $\sim 15 \mathrm{~d}$, they received either E2 $(50 \mu \mathrm{g} / \mathrm{kg}$ of body weight) or vehicle treatment daily for $5 \mathrm{~d}$, followed $1 \mathrm{~d}$ later by kill and tissue processing for histology. In every brain region where OVX produced a decrease in spine density (frontal, motor, and somatosensory cortices plus hippocampal area CA1), subsequent E2 treatment restored the original spine density, whereas vehicle treatment did not (frontal: vehicle $84.56 \pm$ $2.30 \%$ of baseline and E2 $112.37 \pm 2.95 \%$ of baseline, $p<0.001$; motor: vehicle $76.86 \pm 2.83 \%$ of baseline and E2 $118.06 \pm 3.37 \%$ of baseline, $p<0.001$; somatosensory: vehicle $87.46 \pm 2.67 \%$ of baseline and E2 $117.95 \pm 2.70 \%$ of baseline, $p<0.001$; CA1: vehicle $80.03 \pm 1.69 \%$ of baseline and E2 $103.55 \pm 1.38 \%$ of baseline, $p<0.001$; all normalized to each sham group). In occipital cortex, where OVX surgery did not reduce spine density, subsequent E2 treatment still produced a significant increase (vehicle $104.45 \pm 6.19 \%$ of baseline and E2 $123.52 \pm 4.50 \%$ of baseline, $p=0.044$; Fig. $3 A$ ). Our findings in CA1 were consistent with previous studies that systemic injection of E2 increases dendritic spine density in CA1 pyramidal cells in OVX rats (Gould et al., 1990; Woolley and McEwen, 1993; MacLusky et al., 2005; Chen et al., 2009; Phan et al., 2012; Luine et al., 2018). 
A
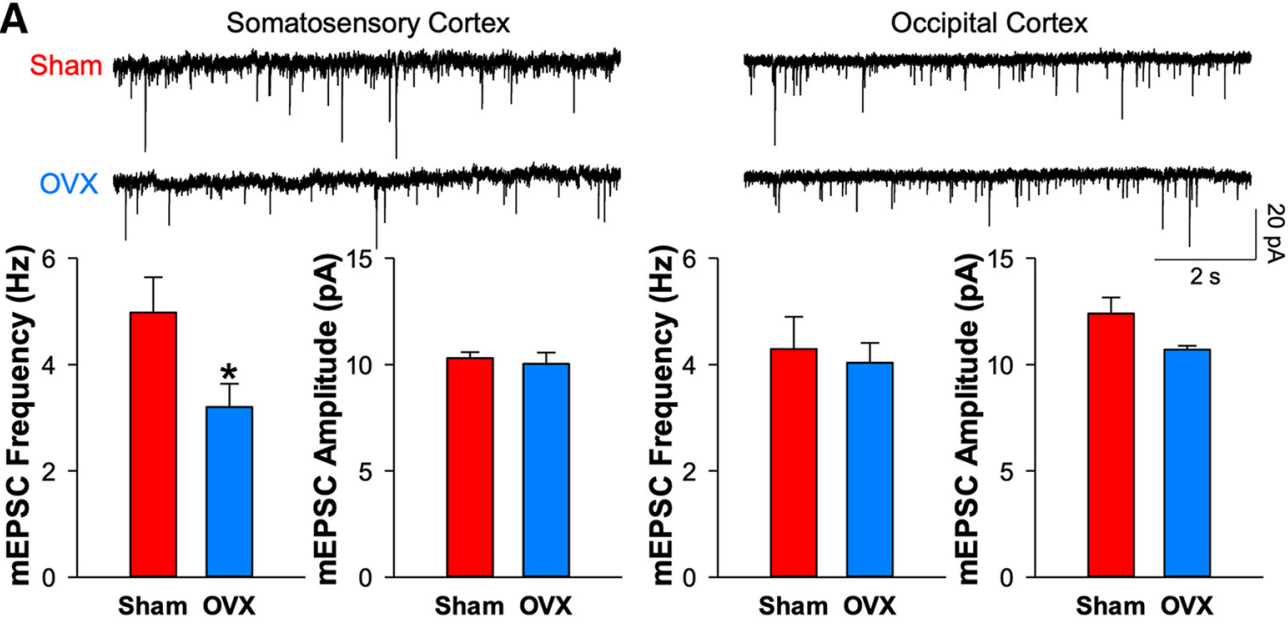

B
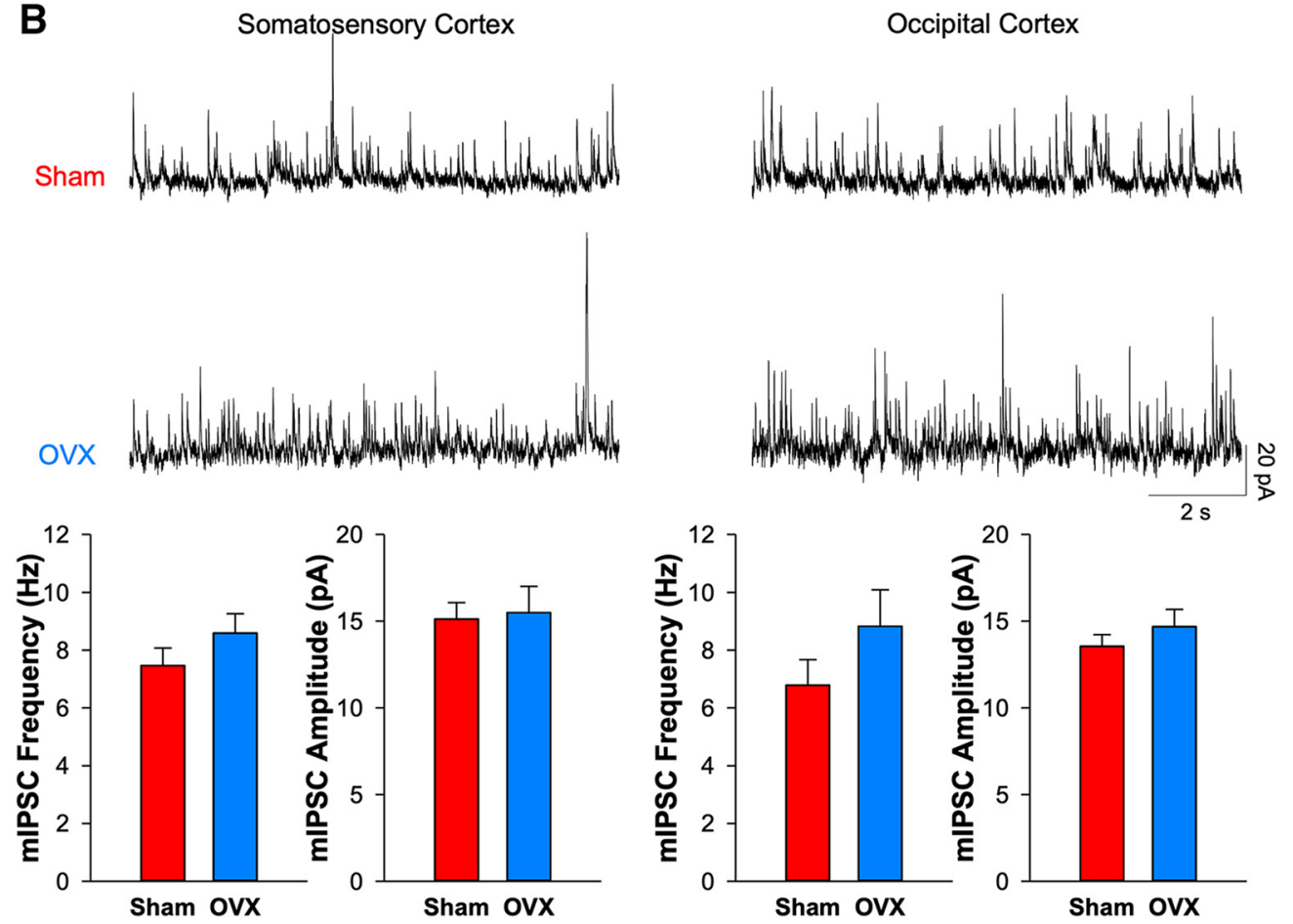

Figure 2. OVX decreases the mEPSC but not mIPSC frequency of layer 5 pyramidal neurons in somatosensory cortex. $A$, Representative traces of mEPSCs recorded from layer 5 pyramidal neurons in somatosensory cortex and occipital cortex. The population bar graphs show the mean frequency and amplitude of mEPSCs from sham and OVX mice $(n=5$ mice for each group; somatosensory cortex: 7 sham cells and 7 OVX cells, $p=0.044$ and $t=2.244$ for frequency, $p=0.626$ and $t=0.471$ for amplitude, $\mathrm{df}=12$; 0 ccipital cortex: 8 sham cells and $70 \mathrm{VX}$ cells, $p=0.734$ and $t=0.347$ for frequency, $p=0.060$ and $t=2.061$ for amplitude, $\mathrm{df}=13$ ). Unpaired two-tailed Student's $t$ test. ${ }^{*} p<0.05$. B, Representative traces showing that mIPSCs recorded from layer 5 pyramidal neurons in somatosensory cortex and occipital cortex are not altered by sham or ovariectomy surgery. Bar graphs show the frequency (somatosensory cortex: 12 sham cells and $100 \mathrm{VX}$ cells, $p=$ $0.113, t=-1.248, \mathrm{df}=20$; 0 ccipital cortex: 9 sham cells and 7 OVX cells, $p=0.097, t=-1.363, \mathrm{df}=14$ ) and amplitude (somatosensory cortex: $p=0.417, t=-0.213 ; 0$ ccipital cortex: $p=$ $0.172, t=-0.978)$ of mIPSCs between sham and OVX mice ( $n=5$ mice for each group). Unpaired two-tailed $t$ test with $p>0.05$ as nonsignificant.

$\mathrm{E} 2$ is an agonist of the estrogen receptors, $\mathrm{ER} \alpha$ and $\mathrm{ER} \beta$, as well as the more recently described non-nuclear GPER (Srivastava and Evans, 2013). To determine which estrogen receptors were necessary for $\mathrm{E} 2$ to produce restoration of spine density, we used selective agonists (Fig. 3A). Treatment of OVX mice with the selective GPER agonist G1 $(6 \mu \mathrm{g} / \mathrm{kg})$ restored spine density in layer 5 pyramidal cells of all of the neocortical areas (frontal cortex: $116.86 \pm 3.82 \%$ of OVX + vehicle values, $p=0.011$; motor cortex: $133.63 \pm 2.91 \%, p<0.001$; somatosensory cortex: $127.31 \pm 2.98 \%, p<0.001$; occipital cortex: $119.87 \pm 2.54 \%, p=$ $0.005)$ but not in CA1 pyramidal cells $(105.04 \pm 1.49 \%, p=$ 0.432). Conversely, a mixture of the ER $\alpha$ agonist PPT and the
$\mathrm{ER} \beta$ agonist DPN ( $1 \mathrm{mg} / \mathrm{kg}$ each) restored spine density in CA1 cells $(125.33 \pm 1.59 \%, p<0.001)$ but not in any of the neocortical layer 5 pyramidal cells (frontal cortex: $86.21 \pm 3.28 \%, p=$ 0.066 ; motor cortex: $111.95 \pm 4.36 \%, p=0.286$; somatosensory cortex: $107.54 \pm 3.88 \%, p=0.682$; occipital cortex: $111.75 \pm$ $5.80 \%, p=0.565)$. Immunoreactivity for GPER, $\mathrm{ER} \alpha$, and $\mathrm{ER} \beta$ was found in the somata of nearly all neocortical layer 5 pyramidal cells and hippocampal CAl pyramidal cells examined. Immunoreactivity in apical dendrites, dendritic spines, and dendritic filopodia of these neurons was much more sporadic (Figs. 4, 5).

The effects of E2 on synaptic function may be rapid. To test this idea, slices of somatosensory cortex were prepared from mice 

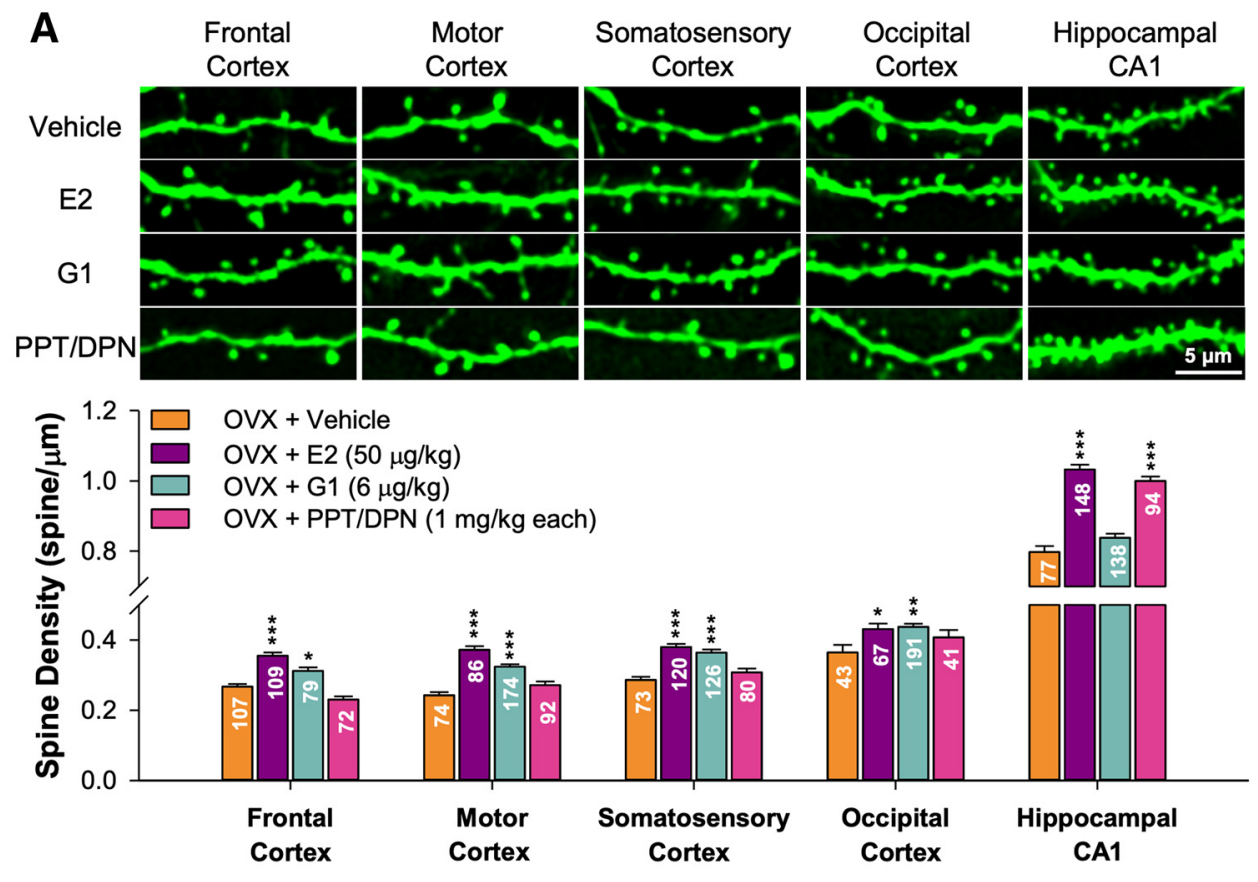

B

Vehicle

Somatosensory Cortex
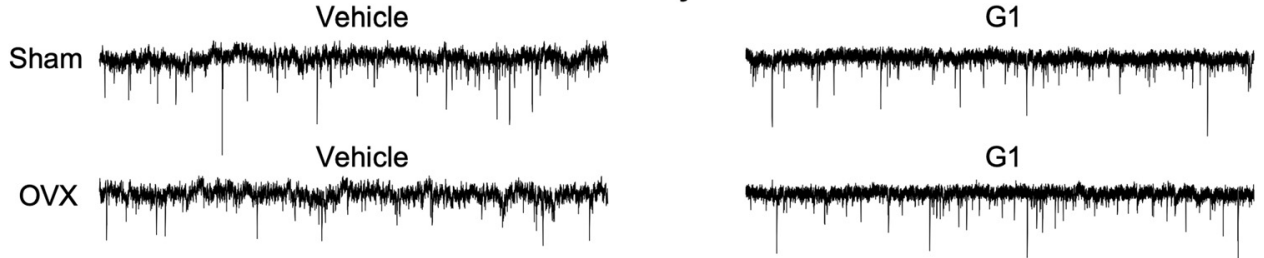

G1

E2
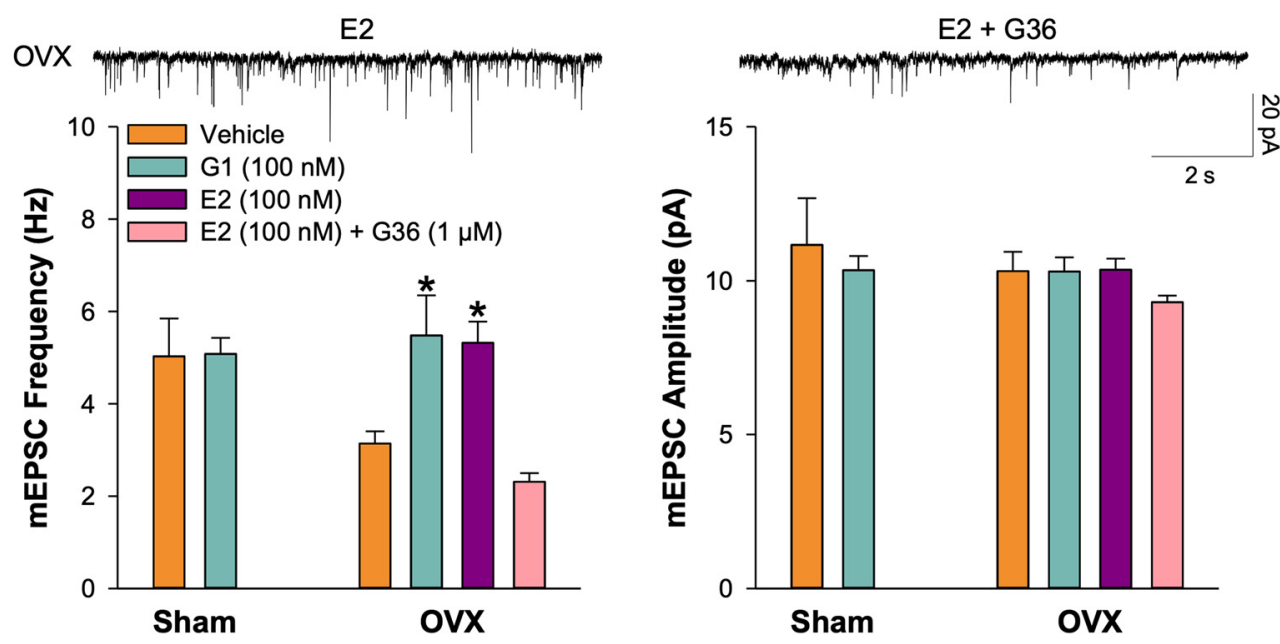

Figure 3. Ovariectomy-induced spine loss was rescued by estradiol and the selective GPER agonist G1 but not selective ER $\alpha / \beta$ agonists in neocortical regions. $A$, The bar graph shows the effects of chronic treatment with vehicle (100 $\mu$ l sesame oil, $n=5$ mice), E2 (50 $\mu \mathrm{g} / \mathrm{kg}, n=5 \mathrm{mice})$, GPER agonist G1 ( $6 \mu \mathrm{g} / \mathrm{kg}, n=4$ mice), and the ER $\alpha / \beta$ agonists PPT/DPN (1 mg $/ \mathrm{kg}$ each, $n=4$ mice) on the OVX-induced spine loss in various neocortical areas and hippocampal CA1 pyramidal cells on mean spine density. The numbers of dendritic segments analyzed in each region were marked in each bar. Exemplar images are shown above. $\boldsymbol{B}$, Representative traces of $\mathrm{mEPSC}$ ( recorded from layer 5 pyramidal neurons in slices of somatosensory cortex of sham mice treated acutely ( $2-3 \mathrm{~h}$ ) with vehicle $(0.01 \%$ DMSO) or G1 (100 nM) or OVX mice treated acutely with vehicle $(0.01 \%$ DMSO), G1 (100 nM), E2 (100 nM), or E2 (100 nM) + the GPER antagonist G36 (1 $\mu \mathrm{m})$. The bar graphs show the effect of treatment with vehicle ( 6 cells from 5 sham and 10 cells from 6 OVX), G1 (10 cells from 4 sham and 10 cells from 4 0VX), E2 (100 nm; 12 cells from 4 OVX mice), and E2 plus G36 (1 $\mu \mathrm{m} ; 12$ cells from 4 OVX mice) on the frequency and amplitude of mEPSCs. Unpaired two-tailed Student's $t$ test for comparing vehicle and G1 in sham mice ( $\boldsymbol{B} ;$ frequency: $p=0.944, t=-0.071$; amplitude: $p=0.540, t=0.629 ; \mathrm{df}=14)$. One-way ANOVA with Bonferroni's post hoc test for comparing drug treatments with vehicle control in $0 \mathrm{VX}$ mice $(A, B) .{ }^{*} p<0.05,{ }^{* *} p<0.01,{ }^{* * * *} p<$ 0.001 .

that had received either sham or OVX surgery $\sim 15 \mathrm{~d}$ before. The brain slices were then incubated for $2-3 \mathrm{~h}$ in external saline supplemented with either vehicle, E2 or G1 (Fig. 3B). Acute E2 treatment restored the decrease in mEPSC frequency produced by
OVX (169.45 $\pm 14.76 \%$ of vehicle, $p=0.022$; Fig. $3 B)$. Consistent with the spine density results (Fig. $3 A$ ), acute G1 treatment restored the decrease in mEPSC frequency in somatosensory cortex neurons produced by OVX surgery (174.77 $\pm 27.83 \%$ of vehicle 

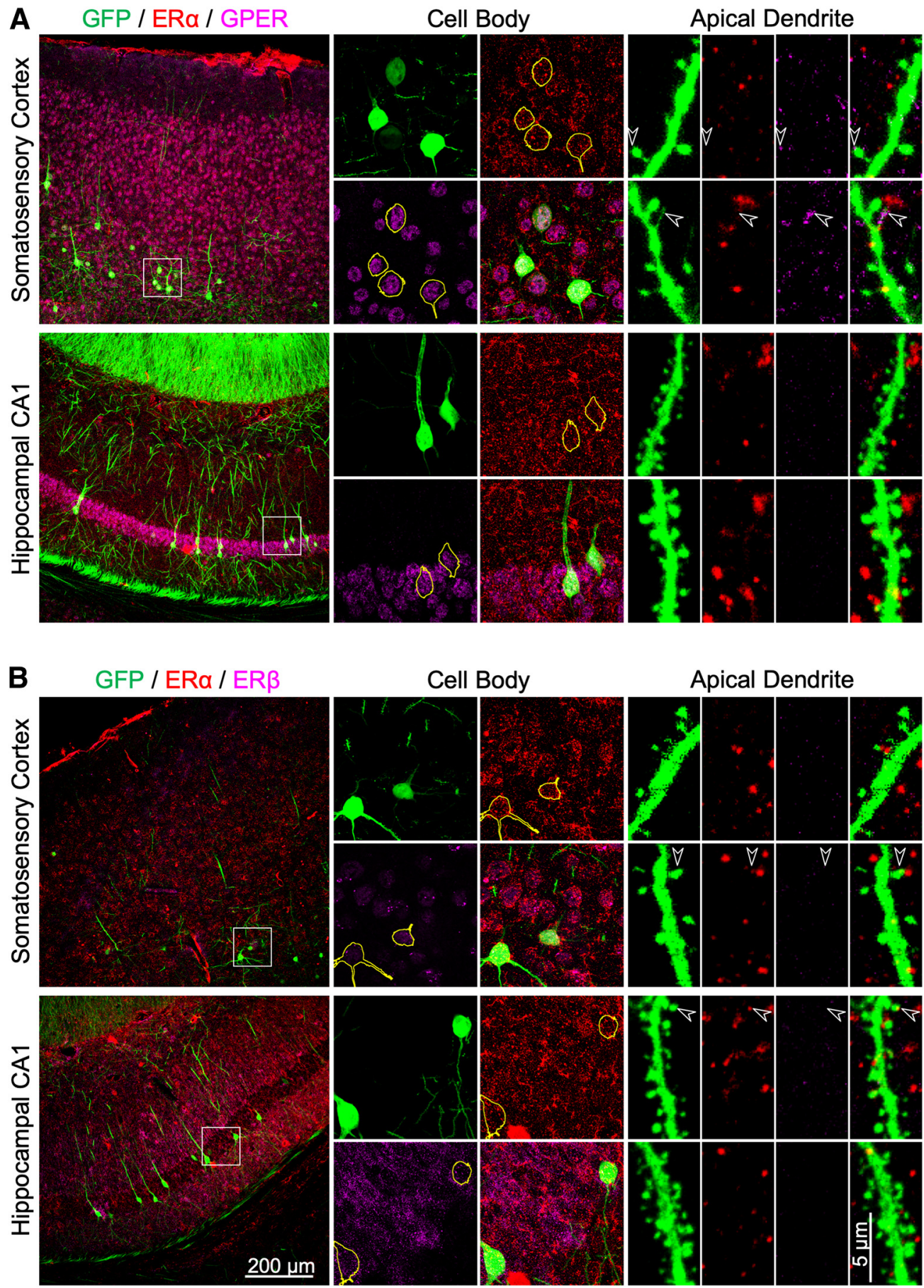

Figure 4. Immunohistochemical staining of $\mathrm{ER} \alpha, \mathrm{ER} \beta$, and GPER in the somatosensory cortex and hippocampal CA1 in intact female Thy1M-GFP mice. $A$, Representative images showing immunostaining of GFP (green), ER $\alpha$ (red), and GPER (magenta) in the soma and distal apical dendrite of neocortical layer 5 and CA1 neurons. GFP-positive somata have been outlined in yellow. The arrowheads indicate colocalization of immunoreactivity in some dendritic spines or filopodia. $\boldsymbol{B}$, Representative images showing the immunostaining of GFP (green), ER $\alpha$ (red), and ER $\beta$ (magenta) in the soma and apical dendrite of layer 5 and CA1 neurons.

treatment, $p=0.017$ ) and the similar effect produced by E2 could be abolished by co-application of the GPER antagonist G36 (1 $\mu \mathrm{M} ; 73.63 \pm 6.18 \%, p=0.741$ compared with vehicle and $p<$ 0.001 compared with E2). G1 had no effect on mEPSC frequency in slices prepared from sham surgery mice $(101.10 \pm 6.88 \%, p=$ 0.944). None of these treatments altered mEPSC amplitude. These results indicate that reversal of the OVX-evoked reduction in functional synaptic density on the apical dendrites of neocortical layer 5 pyramidal cells by E2, as indexed by spine density and
mEPSC frequency, is produced by the rapid action of E2 at GPER but not $\mathrm{ER} \alpha$ or $\mathrm{ER} \beta$ receptors.

To assess the dynamic nature of dendritic spines, cranial windows were implanted overlying the primary somatosensory cortex of young adult ThylM-GFP mice, allowing for time-lapse imaging of the apical dendrites of layer 5 pyramidal neurons. After a $\sim 30 \mathrm{~d}$ long recovery period following the craniotomy, imaging of apical dendrite proceeded every day for 5 consecutive days (d0-d4). Then, later on Day 4, OVX or sham surgery was 
A GFP

GFP

ERa

GPER

Merge

GFP

ERa

GPER Merge
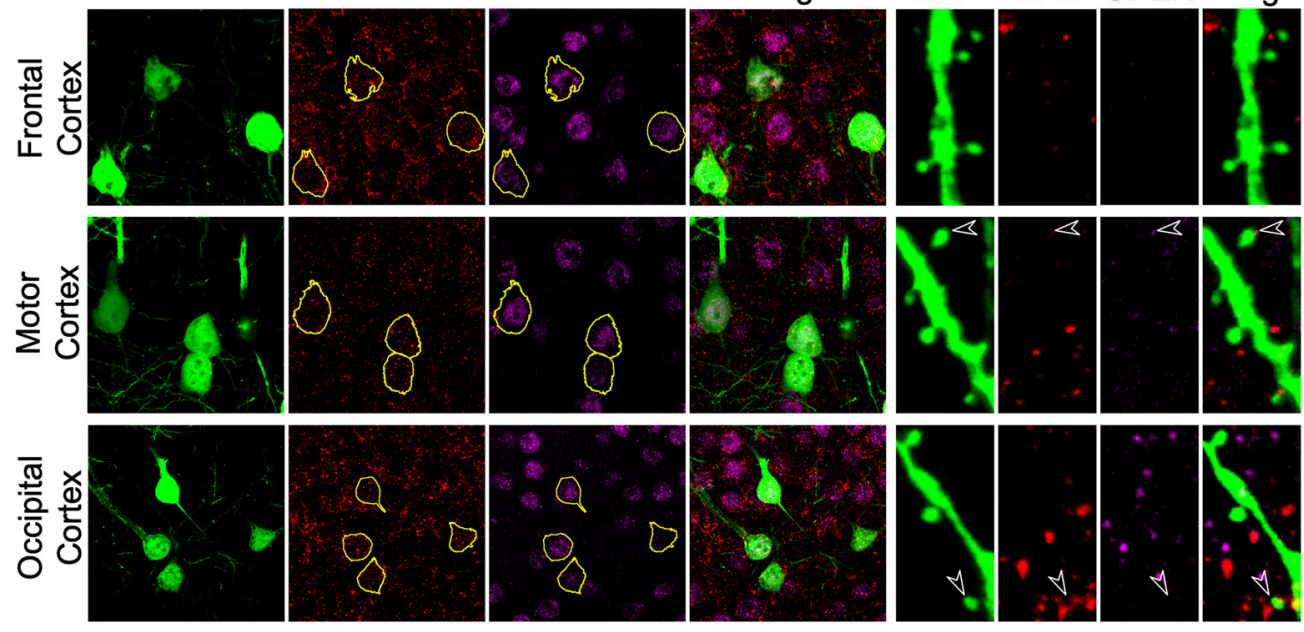

B

GFP

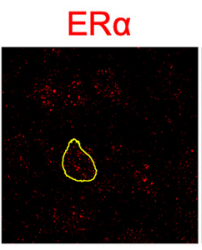

ERß

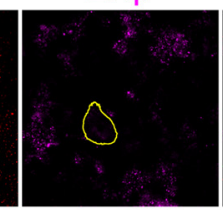

Merge

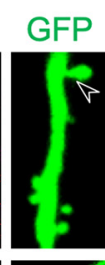

ERa
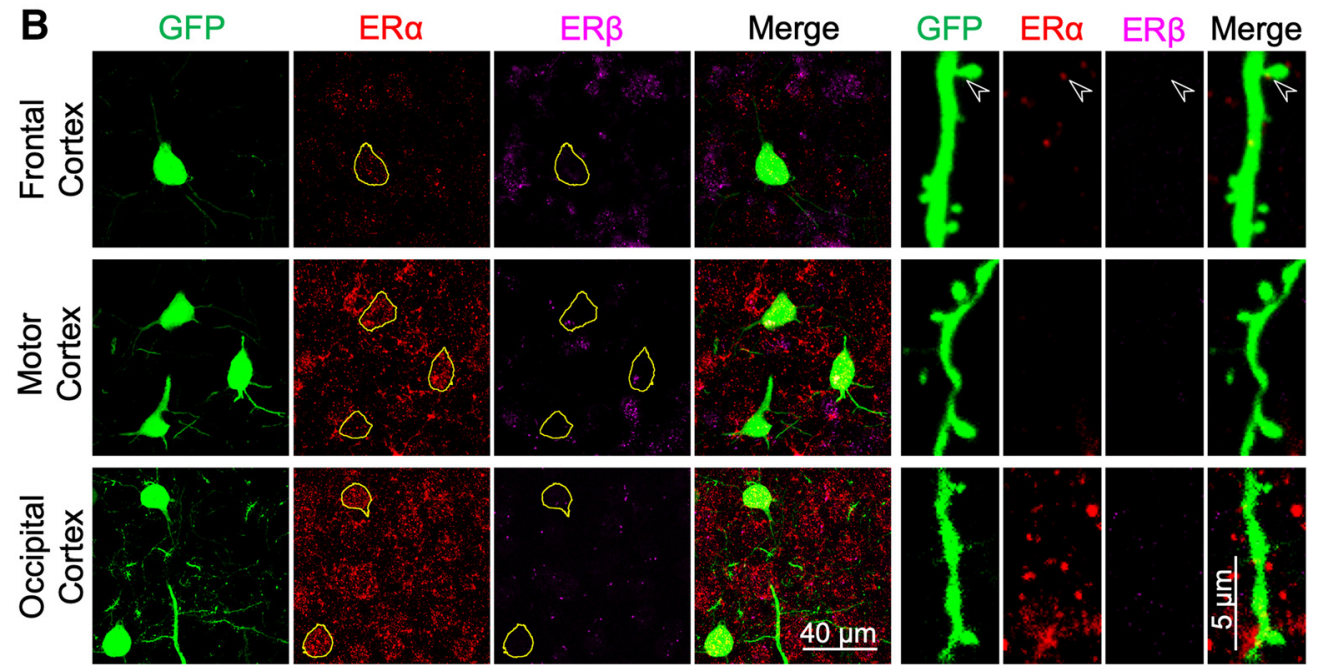

Figure 5. Immunohistochemical staining of $\mathrm{ER} \alpha$, ER $\beta$, and GPER in the frontal, motor and occipital cortices in intact female Thy1M-GFP mice. $A$, Representative images showing immunostaining of GFP (green), ER $\alpha$ (red), and GPER (magenta) in the soma and distal apical dendrite of neocortical layer 5 neurons. GFP-positive somata have been outlined in yellow. The arrowheads indicate colocalization of immunoreactivity in some dendritic spines. $\boldsymbol{B}$, Representative images showing the immunostaining of GFP (green), ER $\alpha$ (red), and ER $\beta$ (magenta) in the soma and apical dendrite of layer 5 neurons.

performed and imaging was resumed on d19 and d20 (Fig. $6 A, B)$. When spine density was measured before $(\mathrm{d} 4)$ and after (d20) these treatments, it was revealed that OVX produced a reduction in spine density $(90.40 \pm 2.30 \%$ of baseline, $n=59$, $p<0.001)$, whereas sham surgery did not $(105.40 \pm 2.80 \%$ of baseline, $n=66, p=0.149$ ), consistent with our previous finding using immunohistochemistry (Fig. 1).

A reduction in spine density can result from a decrease in the rate of spine gain, an increase in the rate of spine loss, or both. By comparing spines over a one-day interval before OVX surgery $(\mathrm{d} 3-\mathrm{d} 4)$ and another $1 \mathrm{~d}$ interval after OVX surgery (d19-d20) we were able to calculate the rate of spine gain and loss (Fig. 6C). We found that comparing these rates before and after OVX surgery showed a significant reduction in both the rate of gain (before: $7.30 \pm 0.61 \%$ spines/d; after: $5.70 \pm 0.56 \%, n=59, p=$ 0.041 ) and an increase in the rate of loss (before: $6.88 \pm 0.55 \%$; after: $9.09 \pm 0.64 \%, n=59, p=0.005$ ) after OVX, which balanced out to yield no change in the TOR (before: $14.18 \pm 0.89 \%$; after: $14.79 \pm 0.83 \%, n=59, p=0.484)$. Sham surgery produced no significant changes in either the rate of gain or loss (gained: $7.62 \pm 0.62 \%$ vs $8.70 \pm 0.62 \%, p=0.188$; lost: $7.44 \pm 0.58 \%$ vs
$8.19 \pm 0.54 \%, p=0.338 ; n=66)$. Moreover, the spine survival rate did not show significant difference between sham and OVX groups $(p=0.676)$.

Previous histological work in hippocampal CA1 pyramidal cells of rats has shown that dendritic spine and glutamatergic synapse density both vary by $\sim 25 \%$ of baseline over the course of the ovarian cycle, being higher in proestrus and late diestrus and lower in estrus (Woolley et al., 1990; Woolley and McEwen, 1992, 1993; Prange-Kiel et al., 2008; Kato et al., 2013). Is this cyclic fluctuation found in the layer 5 pyramidal cell apical dendrite in the mouse? If so, then our measurements would be subject to variation based upon when in the ovarian cycle $\mathrm{d} 4$ or $\mathrm{d} 20$ happened to land in a particular mouse. To assess this possibility, we measured spine density and dynamics for 5 consecutive days in vivo to survey a complete cycle, together with determination of the phase of the ovarian cycle by vaginal smear (Fig. 7A). We found no variation in spine density $(p=0.946)$, rate of spine gain $(p=0.982)$ or loss $(p=0.287)$, or turnover ratio $(p=0.522)$ across the ovarian cycle (Fig. $7 B$ ). This finding is consistent with a previous report examining spine density across the ovarian cycle in adult mouse primary somatosensory cortex layer 5 pyrami- 
A
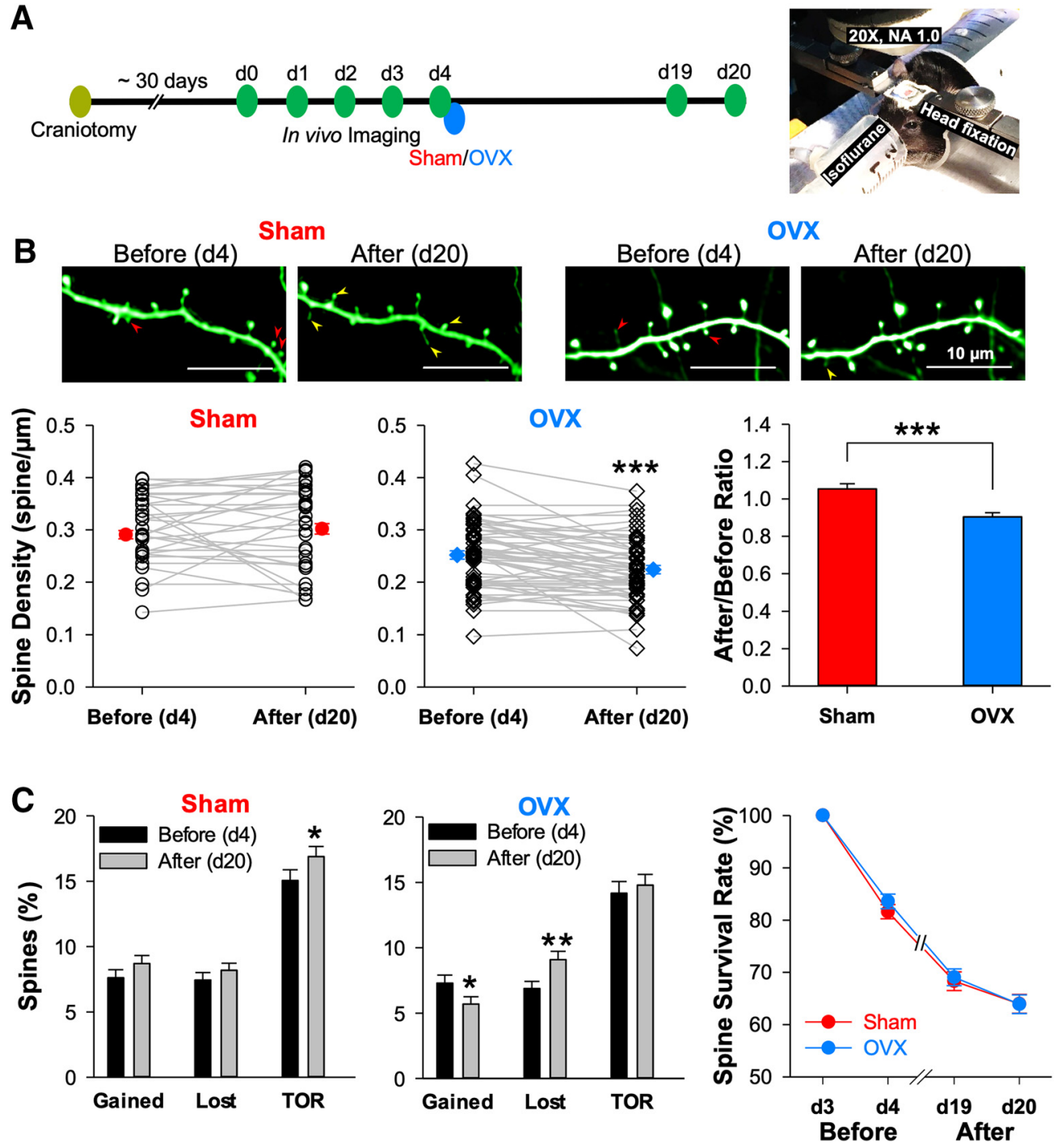

Figure 6. Time-lapse in vivo two-photon imaging reveals that OVX reduces spine density by both increasing the rate of spine loss and decreasing the rate of spine addition. $A$, Left, Time line for experiments using time-lapse two-photon imaging of apical dendrites projected from layer 5 pyramidal neurons in layer 1 region of somatosensory cortex. Right, An isoflurane-anesthetized, head-fixed mouse with chronically implanted cranial window under the two-photon microscope. $\boldsymbol{B}$, Representative images showing a segment of apical dendrite before (d4) and after (d20) sham or OVX surgery. The red arrowheads mark the spines that will later be lost, and the yellow ones mark the newly gained spines. The plots summarize the spine density changes before and after sham (67 dendritic segments from 4 mice) and OVX (59 dendritic segments from 7 mice) surgeries. C, The bar graphs summarize the gained and lost rate, as well as TOR of spines, all calculated by comparing to the previous time point. The line plot shows the survival rate of all spines present on d3. The paired two-tailed Student's $t$ test was used for before/after comparisons, the unpaired two-tailed Student's $t$ test for the sham/OVX group comparisons, and repeat measures two-way ANOVA with Bonferroni's post hoc test for survival rate comparison. ${ }^{*} p<0.05,{ }^{* * *} p<0.001$.

dal neurons, also using in vivo two-photon microscopy which also found no changes in spine dynamics across the ovarian cycle (Alexander et al., 2018). Histological measures of neocortical pyramidal neuron spine density across the ovarian cycle in rats have been variable, with one study showing cyclical variation in primary somatosensory and primary motor cortex (Chen et al., 2009), but others failing to find cyclic variation in the anterior cingulate cortex (Markham and Juraska, 2002) and in a region of the neocortex that was not specified (Prange-Kiel et al., 2008).

We also performed in vivo imaging experiments to assess the dynamic nature of spine density recovery with E2 replacement following OVX surgery (for timeline, see Fig. $8 A$ ). As seen in both histological (Fig. 1) and prior in vivo imaging experiments (Fig. 6), OVX surgery produced a significant reduction in spine density (vehicle treatment group: $92.30 \pm 2.70 \%$ of baseline after OVX, $n=35, p=0.002$; E2 treatment group: $87.20 \pm 3.10 \%$ of baseline after OVX, $n=28, p<0.001$ ) that was reversed with E2
(99.15 $\pm 3.28 \%$ of baseline, $p=1.000$ compared with $\mathrm{d} 4$ baseline and $p<0.001$ compared with $\mathrm{d} 20$ post-OVX) but not vehicle treatment $(93.35 \pm 2.89 \%$ of baseline, $p=0.010$ compared with $\mathrm{d} 4$ and $p=1.000$ compared with $\mathrm{d} 20$; Fig. $8 B$ ). When gain and loss rate were calculate before and after E2 treatment in OVX mice, a significant increase in the rate of gain (before: $5.45 \pm$ $0.83 \%$ of baseline; after: $8.39 \pm 0.83 \%$ of baseline, $n=28, p=$ $0.019)$ was accompanied by a significant decrease in the rate of loss (before: $9.08 \pm 1.04 \%$ of baseline; after: $5.37 \pm 0.69 \%$ of baseline, $p=0.006)$, yielding no change in TOR $(p=0.569$; Fig. $8 C)$. Vehicle treatment produced no change in the rates of spine gain (before: $7.04 \pm 0.94 \%$ of baseline; after: $6.76 \pm 0.0 .74 \%$ of baseline, $n=35, p=0.752$ ) or loss (before: $8.80 \pm 0.76 \%$ of baseline; after: $7.09 \pm 0.99 \%$ of baseline, $p=0.126$ ) in OVX mice. There is also no significant difference of spine survival rate between vehicle and E2 treatment groups $(p=0.579)$. Thus, not just the density of spines in the apical dendrites, but also 
A

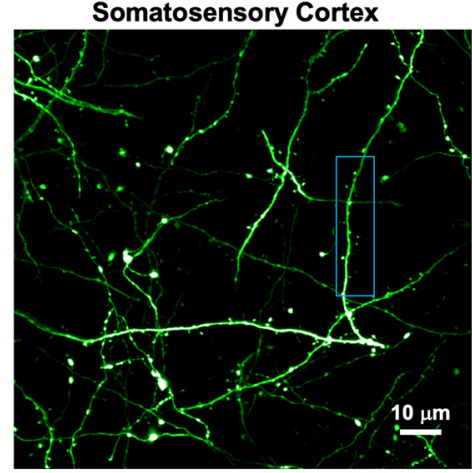

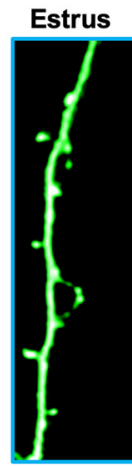
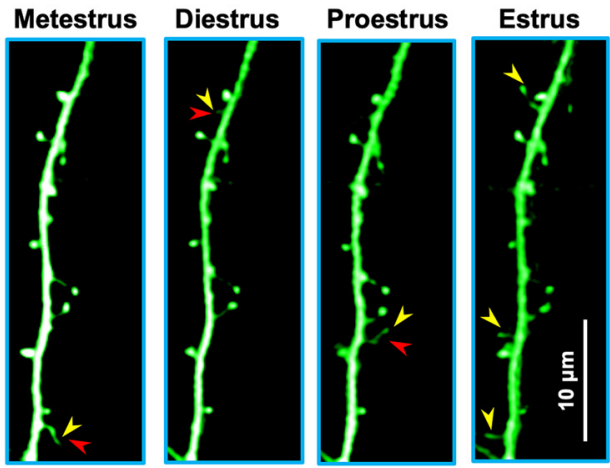

B
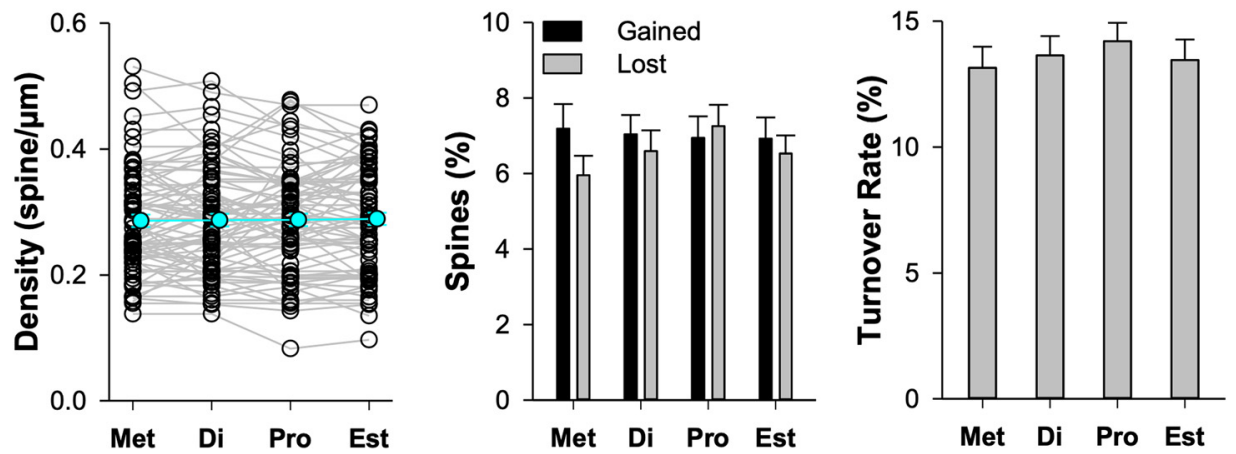

Figure 7. Stable spine density and dynamics across the estrous cycle in somatosensory cortex. $\boldsymbol{A}$, Representative time-lapse images showing a segment of apical dendrite from layer 5 pyramidal neurons in somatosensory cortex. The yellow arrowheads mark the added spine examples, the red ones for lost, and the blue ones marks persistent spines. $\boldsymbol{B}$, The scatter plot shows the spine density changes across the estrous cycle (75 dendritic segments from 5 mice; $p=0.946, F=0.123$ ). The bar graphs summarize gained $(p=0.982, F=0.058)$ and lost rate $(p=0.287, F=1.266)$ as well as TOR ( $p=0.522, F=0.752$ ) of spines, calculated by comparing to the previous time point. The repeated-measures one-way ANOVA test was used for comparison among all five estrus stages $(\mathrm{df}=299)$. The $p>0.05$ was defined as nonsignificant.

their dynamic properties, are reversed with E2 treatment in OVX mice.

There is a certain rate of spine turnover in the apical dendrites of layer 5 pyramidal cells even in the absence of ovariectomy, sham surgery or treatment with exogenous hormones. When spines are gained over time, do they appear at random locations on the dendrite or do they appear preferentially at sites where spines were previously lost? To begin to address this question, we analyzed the data from $\mathrm{d} 1-\mathrm{d} 3$, the period before OVX or sham surgery was performed. Figure $9 A$ shows an exemplar image with stable spines (circled in yellow), a spine that is lost and then gained later at the same location (red) and a spine that is gained at a location that did not previously have a dendritic spine (white). In all cases, careful inspection of single focal planes was performed to assure that the loss and subsequent gain of a spine was not because of it transiently rotating behind the dendritic shaft. The incidence of precise regrowth after loss, nearby regrowth after loss and regrowth nearby existing spines, normalized for the total spines gained, was then plotted for 55 dendritic segments as a cumulative probability histogram.

Putting OVX and its rescue by E2 aside for a moment, is the degree of regrowth at the sites of previous spines what one would expect with purely random ongoing spine turnover? After all, spines have to regrow somewhere and sometimes those random locations will be where a spine was previously. To estimate the regrowth statistics, assuming completely random spine gain, we developed a simple computational model in which the dendritic shaft was divided, on each side, into $0.6 \mu \mathrm{m}$ wide slots and spines were randomly placed one by one. We specified that each slot can only take one spine; therefore, no spines could be added in slots that were currently occupied by the existing spines. This simulation yielded the theoretical distributions shown in Figure 9B. We then compared these theoretical cumulative probability curves with the curves generated from our real experimental data in intact female mice (Fig. 9B; bin size $=0.05$ ), and found that our experimental curve shifted significantly to the right compared with theoretical curve $(p<0.001$, Kolmogorov-Smirnov twosample test), suggesting that, even in the absence of an experimental manipulation, the newly gained spines do indeed preferentially regrow at or nearby sites previously occupied by lost spines. They also preferentially regrow near existing spines $(p<0.001$, Kolmogorov-Smirnov two-sample test).

When spine density is reduced by OVX surgery and this measure is then reversed by exogenous E2 replacement (Fig. 8), is the circuit in the neocortex then returned to its pre-OVX state? One way this reversal could be accomplished would be if spines preferentially regrew at or nearby sites where they had previously been lost. To address this hypothesis, we analyzed spine regrowth over the period $\mathrm{d} 4-\mathrm{d} 25$ in mice that had received OVX surgery followed by either vehicle or E2. Although the overall rate of spine gain (Fig. $8 \mathrm{C}$ ) was significantly higher in the E2 group, those gained spines were no more likely to appear at or nearby the site of previously lost spines or nearby persisting spines than those gained in the vehicle group (Fig. 10). Thus, a model of estrogen replacement therapy, although restoring spine density and dynamics, may not entirely restore functional connectivity.

\section{Discussion}

The original histological studies describing OVX-associated decreases in spine density examined Schaffer-collateral-CA1 pyra- 

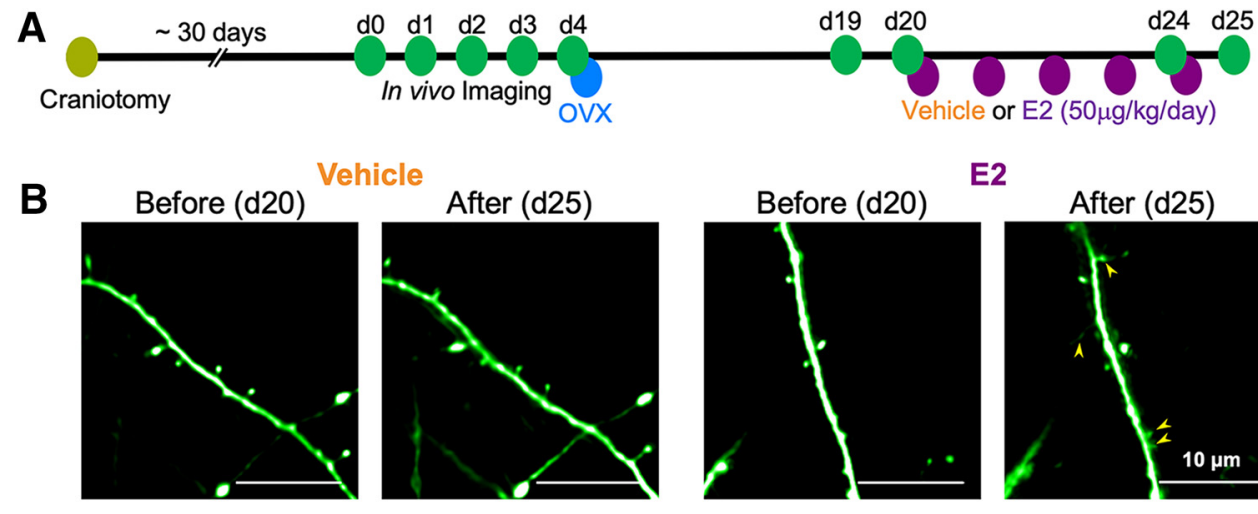

E2
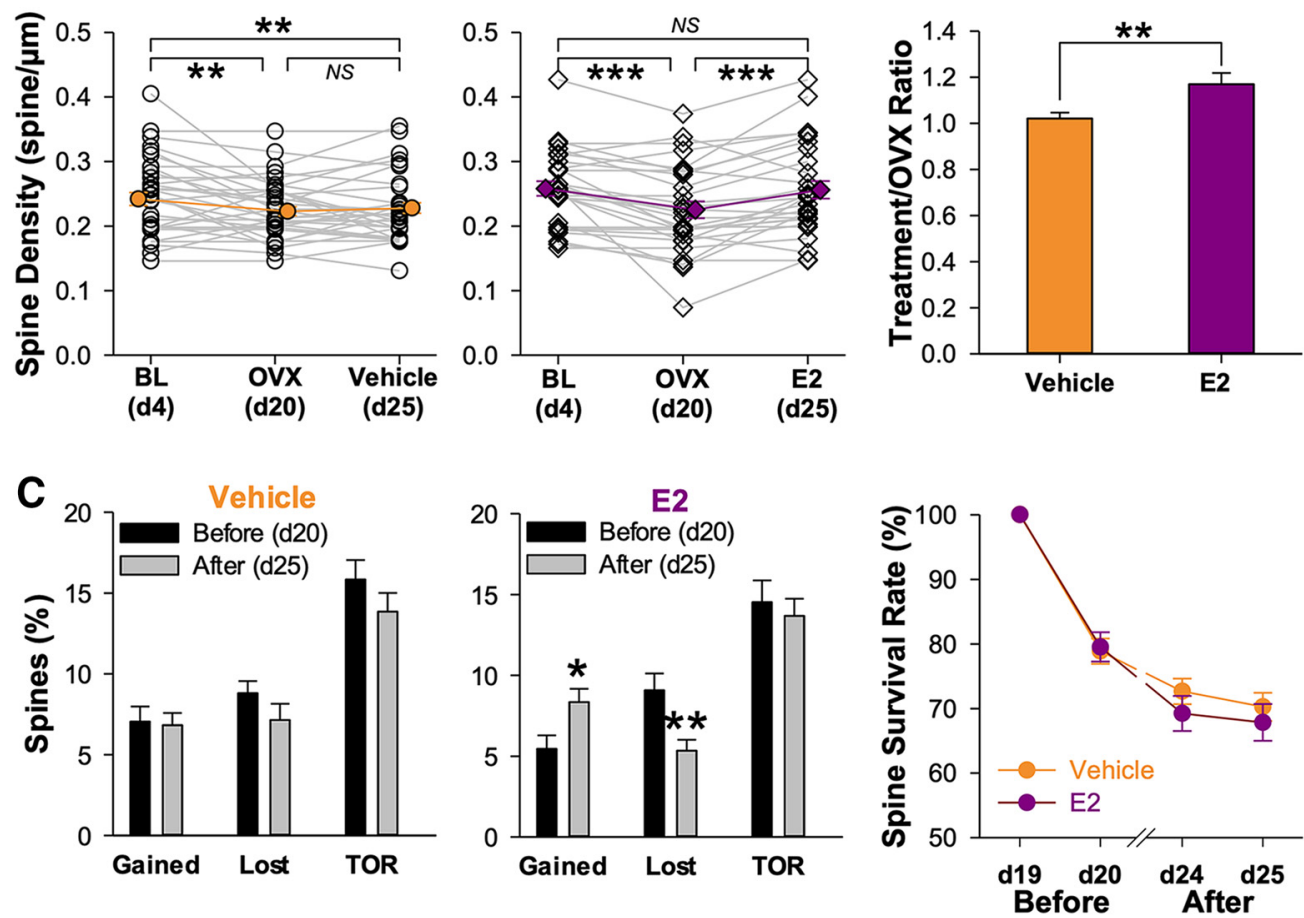

Figure 8. Estradiol replacement rescued OVX-induced spine loss by gaining more and losing less spines. $A$, Experimental design for time-lapse two-photon imaging before and after vehicle or estrogen treatment of OVX mice. $\boldsymbol{B}$, Representative images showing the spine dynamic before (d20) and after (d25) vehicle or E2 treatment. The yellow arrowheads mark the newly gained spines after E2 replacement. The plots summarized the spine density changes before and after vehicle (35 dendritic segments from 4 mice) and E2 (28 dendritic segments from 4 mice) treatments. C, The bar graphs show the gained and lost rate, as well as TOR of spines on various days by comparing them to the previous time point. The line plot showing the survival rate of spines presented in d19. The one-way ANOVA test was used for multigroup comparison $(\boldsymbol{B})$, unpaired two-tailed $t$ test for vehicle/E2 group comparison $(\boldsymbol{B})$, paired two-tailed $t$ test for before/after comparison $(\boldsymbol{C})$, and repeated-measures two-way ANOVA with Bonferroni's post hoc test for survival rate comparison. ${ }^{*} p<0.05$, ${ }^{* *} p<0.01,{ }^{* * *} p<0.001$; NS for $p>0.05$.

midal neuron synapses in the stratum radiatum of rat hippocampus (Gould et al., 1990; Wallace et al., 2006; Zhou et al., 2010). Subsequent investigations have revealed a similar OVXassociated reduction of spine density in the apical and basal dendrites of layer 5 pyramidal neurons of the prefrontal (Wallace et al., 2006), and the apical dendrites of the frontal and primary somatosensory cortices (Chen et al., 2009). Importantly, in some spine-bearing dendrites, such as the apical and basal dendrites of hippocampal CA3 pyramidal neurons, OVX does not appear to reduce synaptic density (Wallace et al., 2006).

Extending previous work done in wild-type rats, we found that OVX surgery was associated with reductions of spine density in the middle third of CA1 stratum radiatum of mice, where mostly Schaffer collateral synapses are received on spines. We also saw OVX-associated reductions in spine density on the apical tuft dendrites of layer 5 pyramidal neurons in fontal, motor and primary somatosensory but not occipital cortex (Fig. 1). This observation is reassuring in that it suggests that the reduction of dendritic spine density is unlikely to result from some general, widespread pathology of spiny dendrites. We do not have a compelling explanation for why occipital cortex is spared. Perhaps, it is related to the lower level of immunoreactivity for GPER30 in occipital cortex compared with motor and somatosensory cortex (Hazell et al., 2009).

Although light microscopy from fixed tissue allows us to image spines, it cannot determine whether these spines receive functional innervation from glutamatergic axons. To address that question, we recorded mEPSCs from layer 5 pyramidal cells in ex vivo slices of somatosensory and occipital cortex, chosen to represent locations with a decrease and no change in spine density, respectively. We found that mEPSC frequency, but not amplitude was reduced in slices of somatosensory cortex from OVX mice compared with those from sham surgery control mice. No reduction in either $\mathrm{mEPSC}$ frequency or amplitude was seen from OVX surgery in occipital cortex (Fig. $2 A$ ). In this way, a physiological measure of functional synapses was consistent with 
A
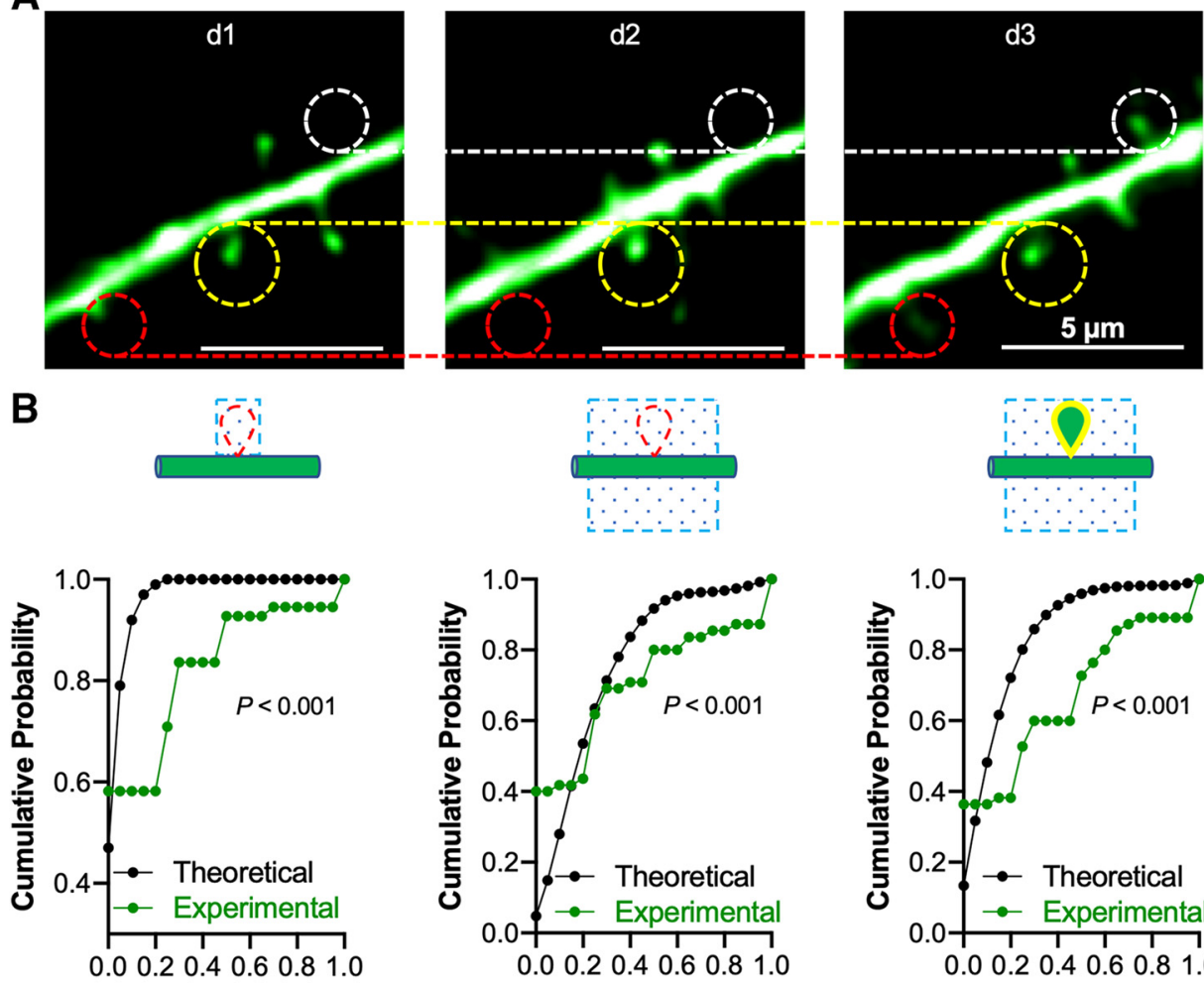

Precise regrowth after loss fraction

Nearby regrowth after loss fraction

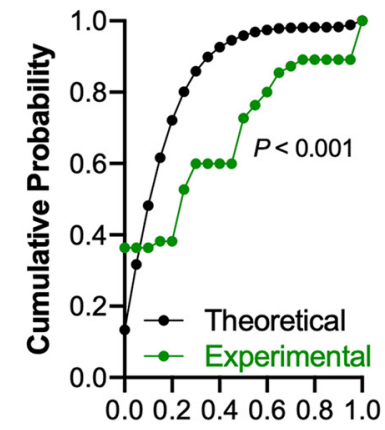

New growth nearby existing spines fraction

Figure 9. Newly gained spines preferentially regrow at or nearby lost spines, or nearby existing spines, even in the absence of perturbation. $\boldsymbol{A}$, Representative images showing the spine dynamics from one intact female mouse (d1-d3). The regrowth of lost spines was analyzed (red circles) with adjacent persistent spines (yellow circles) and new spines (white circles), with the persistent spines used as fiduciary points in all segments, to calculate spine loss and gain compared with $\mathrm{d} 2$. $\boldsymbol{B}$, The cumulative probability curves compared the experimental regrowth probability of 55 dendritic segments from 5 intact mice (normalized to total gained spines), with the theoretical regrowth probability generated from a model of random spine addition; described in Materials and Methods. Left, Spine regrowth at the precise location where a spine was previously lost. Center, Spine regrowth nearby where a spine was previously lost. Right, Spine regrowth nearby existing spines ( $p<$ 0.001 for comparisons in all 3 panels, Kolmogorov-Smirnov two-sample test).

our histological measurement of spine density in these same neurons.

E2 has been shown to reverse the OVX-associated decrease in spine density in both hippocampal area CA1 (Gould et al., 1990; Woolley et al., 1990; MacLusky et al., 2005; Wallace et al., 2006; Phan et al., 2012; Luine et al., 2018) as well as the primary somatosensory and primary motor cortices of the rat (Chen et al., 2009). We have replicated and extended these histological findings by showing that subsequent E2 treatment reverses the OVXassociated decrease in spine density in both hippocampal area CA1 and all of the neocortical regions we surveyed. Notably, E2 treatment increased spine density in layer 5 pyramidal cells of OVX mice in the occipital cortex, even though OVX failed to decrease spine density in these neurons (Fig. 3A). This finding suggests that, in some cases, E2 can evoke increases in spine density even in the absence of prior spine loss.

E2 can exert its actions through the classical estrogen receptors, $\mathrm{ER} \alpha$ and $\mathrm{ER} \beta$, which are localized to the nucleus and act by regulating transcription. More recently, it has been shown that $\operatorname{ER} \alpha$ and $\operatorname{ER} \beta$ are found in the dendrites and spines of some neurons as well (Milner et al., 2001, 2005; Mitterling et al., 2010; Wang et al., 2010; Srivastava et al., 2013). E2 also can act by ligating the non-nuclear G-protein linked estrogen receptor GPER, which is also found in some neurons (Hazell et al., 2009; Hammond et al., 2011; Akama et al., 2013). By using selective agonists of these receptors, G1 for GPER and PPT and DPB for
$\mathrm{ER} \alpha$ and $\mathrm{ER} \beta$, respectively, we have found that reversal of spine density in following OVX surgery in frontal, somatosensory or motor cortex could be produced by activation of GPER but not $\mathrm{ER} \alpha / \mathrm{ER} \beta$. Conversely, in hippocampal area CA1, the reversal of OVX-associated spine density reduction could be produced by a mixture of $\mathrm{ER} \alpha / \mathrm{ER} \beta$ agonists but not a GPER agonist (Fig. $3 A$ ). This observation is consistent with the reported distribution of GPER immunoreactivity in both the male and female adult mouse brain: higher in the somatosensory and motor cortex and lower in area CA1 (Mitra et al., 2003; Merchenthaler et al., 2004; Hazell et al., 2009).

It has been previously described that the effects of E2 on synapses can be rapid (Prossnitz and Maggiolini, 2009; Maggiolini and Picard, 2010; Srivastava and Evans, 2013; Srivastava et al., 2013). We found that acute G1 treatment restored the decrease in mEPSC frequency in layer 5 pyramidal neurons produced by OVX surgery and the similar effect produced by E2 could be abolished by co-application of the GPER antagonist G36. These electrophysiological and histological results suggest that reversal of the OVX-evoked reduction in functional synaptic density on the apical dendrites of neocortical layer 5 pyramidal cells by E2 is produced by the rapid action of $\mathrm{E} 2$ at GPER but not $\mathrm{ER} \alpha$ or ER $\beta$ receptors.

Our histological experiments indicated that layer 5 pyramidal neurons of primary somatosensory cortex would be a good place to investigate spine dynamics with in vivo two-photon imaging. A 

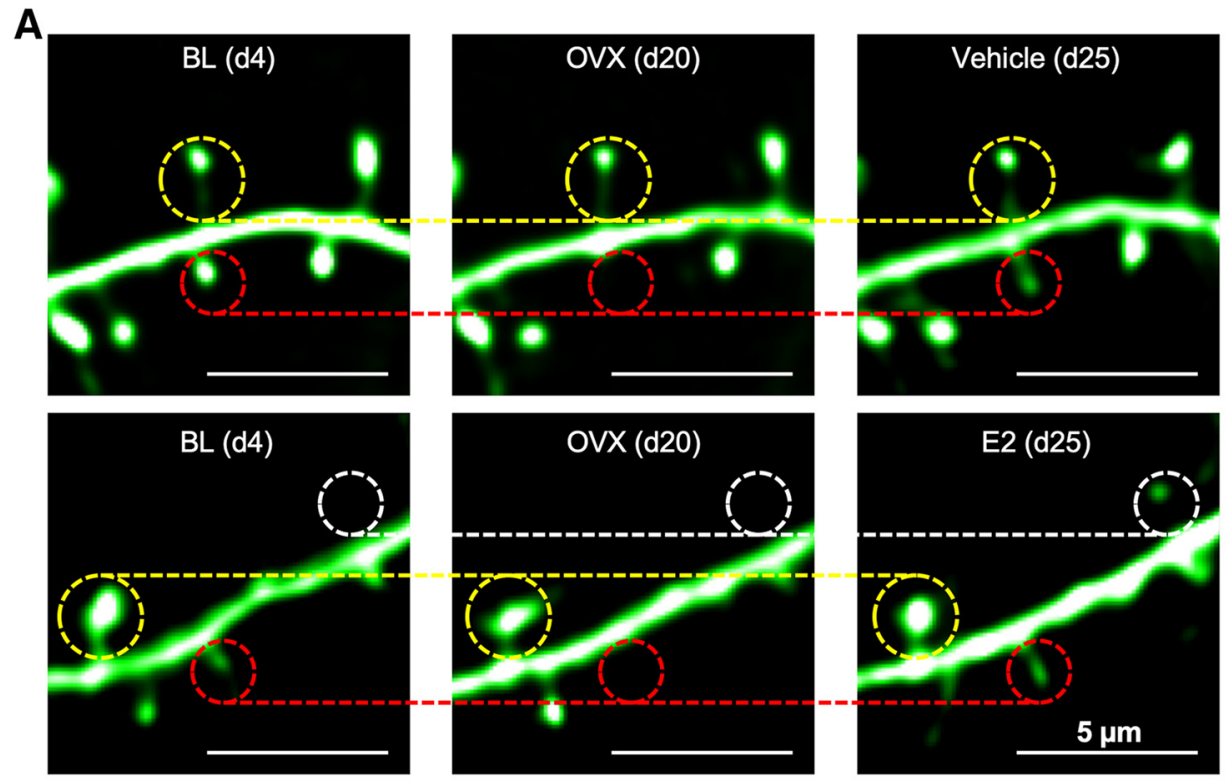

B
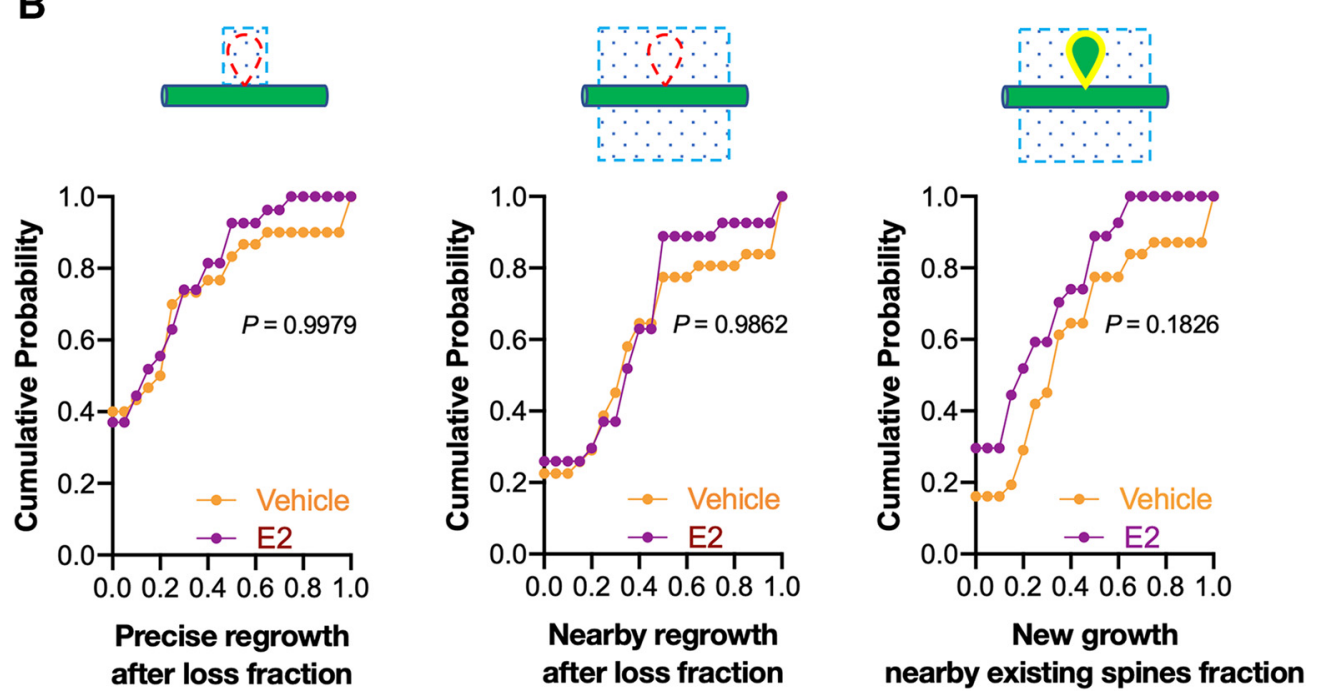

Figure 10. The spines that appear following post-OVX estradiol treatment are no more likely to be located at or nearby sites of previous spine loss or nearby existing spines than those that appear following vehicle treatment. $A$, Representative images showing spine dynamics before OVX (BL; d4), after OVX (d20) and after vehicle or E2 treatment (d25). The regrowth of lost spines was analyzed (red circles) with adjacent persistent spines (yellow circles) and new spines (white circles), with the persistent spines used as fiduciary points in all segments with OVX-induced spine loss and E2 treatment-induced spine gain. $\boldsymbol{B}$, Cumulative probability curves summarized the spine regrowth rate following vehicle (30 dendritic segments from 4 mice) and E2 ( 27 dendritic segments from 4 mice) treatments. Left, Spine regrowth at the precise location where a spine was previously lost. Center, Spine regrowth nearby where a spine was previously lost. Right, Spine regrowth nearby existing spines ( $p>0.10$ for all three comparisons by the Kolmogorov-Smirnov two-sample test).

reduction in spine density, as produced by OVX surgery, could result from an increase in the rate of spine loss, a decrease in the rate of spine gain, or both. Our imaging experiments confirmed the loss of spine density in the apical tuft (Fig. 6A,B) previously seen with histology (Fig. 1) and showed that it was associated with both an increase in the spine loss rate and a decrease in the spine gain rate. These changes were sufficiently offsetting to leave the overall rate of spine turnover unchanged (Fig. 6C). When OVX mice were later treated with $\mathrm{E} 2$, these dynamic processes were reversed. The recovery of spine density produced by E2 (but not vehicle) was associated with both an increase in the rate of spine gain and a decrease in the rate of spine loss (Fig. 8). In this way, not just the density of spines in the apical dendrites, but also their dynamic properties, are reversed following E2 treatment in OVX mice.
Over time, spines are both lost and gained on dendrites. But is the process of spine gain spatially random or are spines more likely to reappear at those locations on the dendrite that previously contained a spine? Here, we measured spines over several days in the absence of any experimental manipulation. When we compared the rate of regrowth of spines at or nearby locations that had previously contained a spine we found that, although it was low, it was notably higher than that predicted by a theoretical simulation of random serial spine addition (Fig. 9A,B). Perhaps, when a spine synapse is lost, there remains behind some biochemical trace- a fragment of undissolved postsynaptic density or a unique structure in the extracellular matrix (or both) that increases the probability of gaining a new spine at that location.

We hypothesized that when the rate of spine addition is increased in OVX mice treated with E2, the proportion of spines 
regrown at sites previously occupied at a pre-OVX time point would increase as well. Our analysis rejected this hypothesis (Fig. 10). When E2 treatment is provided after OVX surgery, spine density recovers, and the spine gain and loss rates recover, but those spines that are added are no more likely to reappear at or near their previous locations than they would with vehicle treatment. In this way, even the regrowth spine density nearby the pre-OVX spines was increased, the ability of E2 to restore the fine details of the neocortical microcircuit is limited.

It should be noted that the OVX surgery will produce effects other than the reduction of estrogens; androgens are likely to be affected as well (Song et al., 2014). In addition, it is well established that the ovaries are not the only source of E2. Indeed, it is now well established that some E2 in the hippocampus and neocortex of the rodent brain remains after OVX surgery and that likely results from local synthesis (Hojo et al., 2008). As such, it is possible that aromatase inhibitor or OVX + aromatase inhibitor treatment would produce further changes to synaptic structure and function beyond what we have demonstrated here.

With the increases in lifespan that have accrued to date, an average woman the United States today can expect to live for $\sim 30$ years in a hypoestrogenic state. A recent meta-analysis has concluded that declines in estrogen that accompany menopause or surgical ovariectomy are associated with significantly reduced performance in delayed verbal memory and verbal fluency tasks as well as increased risk for major depression (Weber et al., 2014). This observation is consistent with findings that estrogen can facilitate working memory and long-term declarative memory in both estrogen-depleted rodents and nonhuman primates (Pompili et al., 2012). The cognitive effects of E2 replacement therapy on women who have entered menopause or undergone ovariectomy is much less clear. Initial studies indicated a clear benefit in verbal and working memory but this effect has not been replicated in some of the larger studies that have followed including the Women's Health Initiative (Fischer et al., 2014). Understanding the dynamic effects of estrogens on synapses in hormone replacement regimes will be central to rationalize, optimize, or perhaps ultimately reject hormone replacement strategies in the clinical setting.

\section{References}

Akama KT, Thompson LI, Milner TA, McEwen BS (2013) Post-synaptic density-95 (PSD-95) binding capacity of G-protein-coupled receptor 30 (GPR30), an estrogen receptor that can be identified in hippocampal dendritic spines. J Biol Chem 288:6438-6450.

Alexander BH, Barnes HM, Trimmer E, Davidson AM, Ogola BO, Lindsey SH, Mostany R (2018) Stable density and dynamics of dendritic spines of cortical neurons across the estrous cycle while expressing differential levels of sensory-evoked plasticity. Front Mol Neurosci 11:83.

Berry KP, Nedivi E (2017) Spine dynamics: are they all the same? Neuron 96:43-55.

Caligioni CS (2009) Assessing reproductive status/stages in mice. Curr Protoc Neurosci 48:A4I.1-A4I.8.

Chen CC, Lu J, Zuo Y (2014) Spatiotemporal dynamics of dendritic spines in the living brain. Front Neuroanat 8:28.

Chen JR, Yan YT, Wang TJ, Chen LJ, Wang YJ, Tseng GF (2009) Gonadal hormones modulate the dendritic spine densities of primary cortical pyramidal neurons in adult female rat. Cereb Cortex 19:2719-2727.

Cudmore RH, Dougherty SE, Linden DJ (2017) Cerebral vascular structure in the motor cortex of adult mice is stable and is not altered by voluntary exercise. J Cereb Blood Flow Metab 37:3725-3743.

Daniel JM, Fader AJ, Spencer AL, Dohanich GP (1997) Estrogen enhances performance of female rats during acquisition of a radial arm task. Horm Behav 32:217-225.

Dumitriu D, Rapp PR, McEwen BS, Morrison JH (2010) Estrogen and the aging brain: an elixir for the weary cortical network. Ann N Y Acad Sci 1204:104-112.
Fader AJ, Johnson PE, Dohanich GP (1999) Estrogen improves working but not reference memory and prevents amnestic effects of scopolamine on a radial arm maze. Pharmacol Biochem Behav 62:711-717.

Feng G, Mellor RH, Bernstein M, Keller-Peck C, Nguyen QT, Wallace M, Nerbonne JM, Lichtman JW, Sanes JR (2000) Imaging neuronal subsets in transgenic mice expressing multiple spectral variants of GFP. Neuron 28:41-51.

Fischer B, Gleason C, Asthana S (2014) Effects of hormone therapy on cognition and mood. Fertil Steril 101:898-904.

Gould E, Woolley CS, Frankfurt M, McEwen BS (1990) Gonadal steroids regulate dendritic spine density in hippocampal pyramidal cells in adulthood. J Neurosci 10:1286-1291.

Hammond R, Nelson D, Gibbs RB (2011) GPR30 co-localizes with cholinergic neurons in the basal forebrain and enhances potassium-stimulated acetylcholine release in the hippocampus. Psychoneuroendocrinology 36:182-192.

Hazell GG, Yao ST, Roper JA, Prossnitz ER, O’Carroll AM, Lolait SJ (2009) Localisation of GPR30, a novel G-protein-coupled oestrogen receptor, suggests multiple functions in rodent brain and peripheral tissues. J Endocrinol 202:223-236.

Hojo Y, Murakami G, Mukai H, Higo S, Hatanaka Y, Ogiue-Ikeda M, Ishii H, Kimoto T, Kawato S (2008) Estrogen synthesis in the brain: role in synaptic plasticity and memory. Mol Cell Endocrinol 290:31-43.

Inagaki T, Frankfurt M, Luine V (2012) Estrogen-induced memory enhancements are blocked by acute bisphenol $\mathrm{A}$ in adult female rats: role of dendritic spines. Endocrinology 153:3357-3367.

Kato A, Hojo Y, Higo S, Komatsuzaki Y, Murakami G, Yoshino H, Uebayashi M, Kawato S (2013) Female hippocampal estrogens have a significant correlation with cyclic fluctuation of hippocampal spines. Front Neural Circuits 7:149.

Luine V, Serrano P, Frankfurt M (2018) Rapid effects on memory consolidation and spine morphology by estradiol in female and male rodents. Horm Behav 104:111-118.

MacLusky NJ, Luine VN, Hajszan T, Leranth C (2005) The $17 \alpha$ and $17 \beta$ isomers of estradiol both induce rapid spine synapse formation in the CA1 hippocampal subfield of ovariectomized female rats. Endocrinology 146:287-293.

Maggiolini M, Picard D (2010) The unfolding stories of GPR30, a new membrane-bound estrogen receptor. J Endocrinol 204:105-114.

Markham JA, Juraska JM (2002) Aging and sex influence the anatomy of the rat anterior cingulate cortex. Neurobiol Aging 23:579-588.

Markram H, Lübke J, Frotscher M, Roth A, Sakmann B (1997) Physiology and anatomy of synaptic connections between thick tufted pyramidal neurones in the developing rat neocortex. J Physiol 500:409-440.

Merchenthaler I, Lane MV, Numan S, Dellovade TL (2004) Distribution of estrogen receptor alpha and beta in the mouse central nervous system: in vivo autoradiographic and immunocytochemical analyses. J Comp Neurol 473:270-291

Milner TA, McEwen BS, Hayashi S, Li CJ, Reagan LP, Alves SE (2001) Ultrastructural evidence that hippocampal alpha estrogen receptors are located at extranuclear sites. J Comp Neurol 429:355-371.

Milner TA, Ayoola K, Drake CT, Herrick SP, Tabori NE, McEwen BS, Warrier S, Alves SE (2005) Ultrastructural localization of estrogen receptor beta immunoreactivity in the rat hippocampal formation. J Comp Neurol 491:81-95.

Mitra SW, Hoskin E, Yudkovitz J, Pear L, Wilkinson HA, Hayashi S, Pfaff DW, Ogawa S, Rohrer SP, Schaeffer JM, McEwen BS, Alves SE (2003) Immunolocalization of estrogen receptor beta in the mouse brain: comparison with estrogen receptor alpha. Endocrinology 144:2055-2067.

Mitterling KL, Spencer JL, Dziedzic N, Shenoy S, McCarthy K, Waters EM, McEwen BS, Milner TA (2010) Cellular and subcellular localization of estrogen and progestin receptor immunoreactivities in the mouse hippocampus. J Comp Neurol 518:2729-2743.

Phan A, Gabor CS, Favaro KJ, Kaschack S, Armstrong JN, MacLusky NJ, Choleris E (2012) Low doses of $17 \beta$-estradiol rapidly improve learning and increase hippocampal dendritic spines. Neuropsychopharmacology 37:2299-2309.

Pompili A, Arnone B, Gasbarri A (2012) Estrogens and memory in physiological and neuropathological conditions. Psychoneuroendocrinology 37:1379-1396.

Prange-Kiel J, Jarry H, Schoen M, Kohlmann P, Lohse C, Zhou L, Rune GM (2008) Gonadotropin-releasing hormone regulates spine density via its 
regulatory role in hippocampal estrogen synthesis. J Cell Biol 180:417426.

Prossnitz ER, Maggiolini M (2009) Mechanisms of estrogen signaling and gene expression via GPR30. Mol Cell Endocrinol 308:32-38.

Song X, Zhao P, Wang G, Zhao X (2014) The effects of estrogen and androgen on tear secretion and matrix metalloproteinase-2 expression in lacrimal glands of ovariectomized rats. Invest Ophthalmol Vis Sci 55:745-751.

Srivastava DP, Woolfrey KM, Woolfrey K, Jones KA, Shum CY, Lash LL, Swanson GT, Penzes P (2008) Rapid enhancement of two-step wiring plasticity by estrogen and NMDA receptor activity. Proc Natl Acad Sci U S A 105:14650-14655.

Srivastava DP, Evans PD (2013) G-protein oestrogen receptor 1: trials and tribulations of a membrane oestrogen receptor. J Neuroendocrinol 25:1219-1230.

Srivastava DP, Woolfrey KM, Penzes P (2013) Insights into rapid modulation of neuroplasticity by brain estrogens. Pharmacol Rev 65:1318-1350.

Tjia M, Yu X, Jammu LS, Lu J, Zuo Y (2017) Pyramidal neurons in different cortical layers exhibit distinct dynamics and plasticity of apical dendritic spines. Front Neural Circuits 11:43.

Wallace M, Luine V, Arellanos A, Frankfurt M (2006) Ovariectomized rats show decreased recognition memory and spine density in the hippocampus and prefrontal cortex. Brain Res 1126:176-182.

Wang AC, Hara Y, Janssen WG, Rapp PR, Morrison JH (2010) Synaptic estrogen receptor-alpha levels in prefrontal cortex in female rhesus monkeys and their correlation with cognitive performance. J Neurosci 30: $12770-12776$.
Wang S, Zhu J, Xu T (2018) 17 $\beta$-estradiol (E2) promotes growth and stability of new dendritic spines via estrogen receptor $\beta$ pathway in intact mouse cortex. Brain Res Bull 137:241-248.

Weber MT, Maki PM, McDermott MP (2014) Cognition and mood in perimenopause: a systematic review and meta-analysis. J Steroid Biochem Mol Biol 142:90-98.

Woolley CS, McEwen BS (1992) Estradiol mediates fluctuation in hippocampal synapse density during the estrous cycle in the adult rat. J Neurosci 12:2549-2554.

Woolley CS, McEwen BS (1993) Roles of estradiol and progesterone in regulation of hippocampal dendritic spine density during the estrous cycle in the rat. J Comp Neurol 336:293-306.

Woolley CS, Wenzel HJ, Schwartzkroin PA (1996) Estradiol increases the frequency of multiple synapse boutons in the hippocampal CA1 region of the adult female rat. J Comp Neurol 373:108-117.

Woolley CS, Gould E, Frankfurt M, McEwen BS (1990) Naturally occurring fluctuation in dendritic spine density on adult hippocampal pyramidal neurons. J Neurosci 10:4035-4039.

Yankova M, Hart SA, Woolley CS (2001) Estrogen increases synaptic connectivity between single presynaptic inputs and multiple postsynaptic CA1 pyramidal cells: a serial electron-microscopic study. Proc Natl Acad Sci U S A 98:3525-3530.

Zhou L, Fester L, von Blittersdorff B, Hassu B, Nogens H, Prange-Kiel J, Jarry H, Wegscheider K, Rune GM (2010) Aromatase inhibitors induce spine synapse loss in the hippocampus of ovariectomized mice. Endocrinology 151:1153-1160. 